This is the version of the article accepted for publication in a forthcoming issue of Financial Management published by Wiley: http://onlinelibrary.wiley.com/journal/10.1111/(ISSN)1755-053X/issues

Accepted version downloaded from SOAS Research Online: http://eprints.soas.ac.uk/24713/

\title{
Sold Below Value? Why Takeover Offers Can Have Negative Premiums
}

\section{Utz Weitzel, Universiteit Utrecht}

\section{Gerhard Kling, School of Finance and Management, SOAS University of London}

Many studies have acknowledged the existence of negative offer premiums where the initial bid undercuts the target's pre-announcement market price. However, this phenomenon has not been explained. Negative premiums occur frequently and are no measurement error. We demonstrate theoretically and empirically that "hidden earnouts," where target shareholders participate in the bidder's share of joint synergies, and corrections of overvaluation explain negative premiums. We find that target shareholders profit from the consummation of a takeover even if the announced offer has a negative premium. Our theory generalizes to low positive premiums with predictive power for the bottom $25 \%$ of all premiums.

Utz Weitzel is a Professor of Finance and Financial Markets in the School of Economics at Utrecht University and a Professor of Experimental and Behavioral Finance in the Institute for Management Research at Radboud University, IMR, The Netherlands.

Gerhard Kling is a Professor of International Business and Management in the School of Finance and Management at SOAS University of London, London, UK.

We are grateful to Rajkamal Iyer and would like to thank the anonymous referee for many constructive comments and suggestions. We would like to acknowledge the excellent copy-editing service provided by Wendy Jennings. 
Suppose a bidder proposes to purchase a target for less than its market value before the announcement. Should a target give such a bid any thought? On January 14, 2005, common stock of Computer Network Technology Corporation (CNT) traded at \$6.62 (NASDAQ closing price). The following business day, McData Corporation announced its intention to acquire CNT in a stock swap offering 1.3 shares of its NASDAQ-listed Class A common stock for each share of CNT. Based on McData’s closing stock price of \$4.25, the bid valued each CNT share at $\$ 5.525(1.3 \times \$ 4.25)$ resulting in a negative premium of $-16.5 \%$. This is not a measurement error and is consistent with Thomson's M\&A tear sheet. ${ }^{1}$ Aside from the negative premium, the takeover was not unusual. McData sought to acquire $100 \%$ of CNT's shares and had no toehold. CNT experienced losses, but was not bankrupt. The offer was supported by CNT's management, approved by CNT's shareholders, and completed on June 1, 2005 under the terms of the initial bid without competing offers.

Our US sample indicates that this is not an isolated case. On average, $8.4 \%$ of all mergers and acquisitions (M\&As) exhibit negative premiums from 1995-2011, reaching a peak of $14.1 \%$ in 2004 . While the average premium in the sample period is $43.2 \%$, the average size of the negative premiums is $15.5 \%$. Although there are several technical reasons for negative premiums, primarily related to measurement issues, we find that negative premiums still exist after correcting for, among others, adverse market movements, multiple deals, selfdealing, legal or regulatory restrictions, reverse mergers, announcement date inaccuracies, and marginal deviations of premiums from zero. Our findings hold for a broad range of premium measures based on the very first announcement of a takeover offer including market return

\footnotetext{
${ }^{1}$ Changing the reference point, such as four or eight weeks prior to the bid, still leads to a negative premium of $-16.3 \%$ and $-1.9 \%$, respectively. The bid was also below CNT's average share price in $2004(\$ 6.30)$ and in 2003 (\$7.91).
} 
corrections, different windows, and various premium thresholds below and above zero. For data quality reasons, we restrict our analyses to domestic U.S. mergers. However, in an exploratory extension, Table VIII indicates that negative premiums are a worldwide phenomenon.

Earlier studies have acknowledged the existence of negative premiums (Dong, Hirshleifer, Richardson, and Teoh, 2006; Moeller, Schlingemann, and Stulz, 2004; Bates and Lemmon, 2003; Officer, 2003, 2007; Schwert, 1996). Yet no explanation has been offered. This paper provides theoretical and empirical evidence that negative premiums exist and can be explained rationally. Target shareholders need to be convinced that, ultimately, they will gain from the merger. Thus, a theory attempting to explain negative offer premiums must allow for positive post-merger premiums for target shareholders. We propose three explanations for negative premiums assuming rational, forward-looking shareholders whose decisions are based on new information revealed by the offer.

The first explanation hinges on the fact that bidders pay with ownership when offering a consideration in stock. Target shareholders profit twice from merger synergies. First, they negotiate a share of synergies included in the offer premium through the share exchange ratio. Second, they participate in the bidder's share of synergies that accrue to the merged entity through the target shareholders' ownership in the joint entity. We designate the latter as "hidden earnouts" as they are hidden in the bidder's negotiated share and conditional upon synergy realization after consummation of the merger. If the bidder offers less than the target's market value, a favorable share exchange ratio could provide target shareholders with sufficient ownership such that hidden earnouts make the deal worthwhile. In fact, if the target is relatively large, a combination of negative premiums and hidden earnouts can be the only 
option for the bidder to pay the target in stock without losing control over the merged entity. As hidden earnouts cannot be explicitly included in a bid, the market reaction to such an announcement should be positive.

The second explanation refers to overvaluation as a target's stand-alone market value could exceed a fair bid constituting a negative offer premium. Bidders could detect overvaluation while conducting valuations prior to the offer (Boone and Mulherin, 2007). The target management might accept a negative premium fearing that the overvaluation may soon be public knowledge. If the target is overvalued, the market should react to the announcement of a negative premium with negative abnormal returns, thus correcting the mispricing. ${ }^{2}$ The lower post-announcement share price then reflects the bid consisting of the target's fair standalone value plus a positive premium. As an alternative to overvaluation of a target's fundamentals, pre-bid run-ups can constitute speculative overvaluation of anticipated merger gains to the target (Betton, Eckbo, Thompson, and Thorburn, 2014). Excessive run-ups may overshoot the announced offer resulting in a negative premium and a subsequent negative market reaction.

The third explanation pertains to liquidity in the market for corporate control. Discounts in illiquid markets for corporate assets can severely depress M\&A transaction prices (Schlingemann, Stulz, and Walkling, 2002). If targets are financially constrained or distressed, market illiquidity can push prices below fundamental values, as in fire sales (Shleifer and Vishny, 1992).

\footnotetext{
${ }^{2}$ CNT's fiscal year ended 13 days after the announcement of McData's offer. In the annual report, published prior to the consummation of the merger, CNT's management warned that "we may not be able to achieve (...) profitability," that "we may be significantly harmed if we do not complete the pending merger," and that "we have significant indebtedness." CNT shares fell \$1 to \$5.62 at the announcement. McData shares rose 11 cents to $\$ 4.36$ and $\$ 5$ at consummation. Thus, CNT’s offer premium and mark-up were negative.
} 
Our empirical tests indicate that hidden earnouts explain negative premiums, particularly when bidders offer high equity portions for relatively large targets. As expected, the market reacts positively to negative premiums with sufficiently high hidden earnouts as target shareholders anticipate post-merger gains. We also find support for overvaluation, both of a target's fundamental value and, notably, of anticipated merger gains (i.e., run-ups). As expected, the market reaction to these announcements is negative. The explanatory power of market liquidity is limited with weak support for M\&A transaction volumes and financial constraints.

This paper contributes to the growing literature on target premiums (Betton, Eckbo, and Thorburn, 2008; Eckbo, 2009). For the first time, we present theoretical and empirical evidence for negative premiums emerging from rational behavior. The broader implications of this finding go beyond negative premiums. In extensions of our analyses, we find that negative premiums are the tip of the iceberg of low positive premiums. Our theory and empirical results also hold for this much larger phenomenon. In fact, we find that our theory generalizes to the bottom $25 \%$ of all premiums.

Our results have managerial implications for bidders as hidden earnouts can be used to negotiate lower offer prices. This particularly applies to bidders with strong long-term growth perspectives. Our theory also derives a direct measure for hidden earnouts, which can be estimated. Finally, for managers and shareholders of targets, we provide an answer to the opening question: should a target give a bid with a negative premium any thought? Yes, as hidden earnouts and corrections for overvaluation could make the deal worthwhile. 


\section{Theoretical Explanations}

\section{A. Preliminaries}

To simplify matters, we make five assumptions. Table I summarizes the variables and definitions.

A-1. Bidders acquire $100 \%$ of targets' shares and do not have a toehold.

A-2. Bidders and targets have one type of (common) stock.

A-3. Bidders and targets know fundamental values prior to the bid.

A-4. When the bid is announced, fundamental values are public knowledge.

A-5. One initial bid without subsequent improvements or competing bids.

Insert Table I about here.

In line with (Betton et al., 2014, 2008), we compute premiums at the announcement of a takeover offer and refer to them either as offer premiums or simply premiums.

$$
p=\frac{b}{v^{T}}-1
$$

$b>0$ is the value of the initial public bid for a target at the announcement and $v^{T}>0$ is the target's stand-alone market value prior to the bid. The bid, $b$, includes an equity component, 
$e b$, and a cash component, $(1-e) b . X$ is the share exchange ratio, $K^{B}$ is the bidder's share price, and $N^{T}$ is the number of target's shares outstanding.

$$
b=e b+(1-e) b=X K^{B} N^{T}+(1-e) b
$$

After consummation, the share price of the merged entity, $K^{M}$, reflects fundamental values (A-4), $v_{f}^{B}+v_{f}^{T}$, synergies, $s$, and the cash outflow, $(1-e) b$, divided by the total number of post-merger stock outstanding. ${ }^{3}$

$$
K^{M}=\frac{v_{f}^{B}+v_{f}^{T}+s-(1-e) b}{N^{B}+X N^{T}}
$$

The post-merger value of the bid, $b_{m}$, consists of the revalued equity portion and the unchanged cash component. The revalued equity portion refers to the share price, $K^{M}$, and not the bidder's pre-bid share price, $K^{B}$. As the share exchange ratio, $X$, is fixed (A-5), it reflects the number of post-merger shares in the combined firm held by target shareholders per premerger share. ${ }^{4}$

$$
b_{m}=X K^{M} N^{T}+(1-e) b
$$

\footnotetext{
${ }^{3}$ Whether the bidder finances the cash component through debt or cash holdings does not alter the argument. Excess cash has a market-to-book ratio of one. Increasing debt by one unit reduces the value of equity by one unit as the entity value does not change. Thus, the outflow of cash to target shareholders reduces the value of the merged entity.

${ }^{4}$ The fact that $X$ is fixed does not exclude bid revisions or contractual devices (e.g., collars) (Officer, 2004, 2006). Theoretically, each adjustment to a new $X$ constitutes a new bid. Empirically, we control for collars and multiple bids.
} 
Analogously to Equation (1), the premium after consummation, hereafter referred to as the post-merger premium, $p_{m}$, can be defined using Equations (3), (4) and A-4.

$$
p_{m}=\frac{b_{m}}{v_{f}^{T}}-1
$$

To approve the deal, target shareholders must anticipate that they will eventually benefit (Participation Constraint). The post-merger premium must be strictly positive, $\mathrm{p}_{\mathrm{m}}>0$. Note that for post-merger events, we implicitly argue in expected terms. At or directly after the announcement, shareholders do not know the realization of $p_{m}, b_{m}$, or $s$, but they form rational expectations based on all currently available information. According to Equation (1), two approaches can explain negative premiums: 1) focusing on the initial bid and explaining why $b$ $<v_{f}^{T}$ and 2) focusing on the target's stand-alone valuation and explaining why $v^{T}>b$.

\section{B. Hidden Earnouts $\left(b<\mathbf{v f}^{\mathrm{T}}\right)$}

When the target's stand-alone value is fair, a bid below the fundamental value results in a negative premium $\left(b<v_{f}^{T}=v^{T}\right)$. A distinction must be made between stock swaps and other forms of payment. In stock swaps, the bidder partially transfers ownership and, in doing so, effectively pays more than announced in the offer. If the bid includes a portion, $1-\lambda$, of synergies, $s$, for the bidder, target shareholders receive two types of equity-based earnouts: 1) one that is announced in the exchange rate, $X$, of the bid, and 2) one that is hidden. The former is the target's share of synergies, $\lambda s$, in the offer premium, $p$. The latter, hereafter referred to as Hidden Earnouts $\pi_{h}$, is part of the post-merger premium $p_{m}$, which includes the target shareholders' participation in the bidder's share of joint synergies. Thus, the relationship 
between the two premiums is $p_{m}=p+\pi_{h}$, effectively defining hidden earnouts as $\pi_{h}=p_{m}-p$.

Lemma 1 presents the existence of hidden earnouts. The Web Appendix A contains all proofs.

\section{Lemma 1. Existence of Hidden Earnouts}

Hidden earnouts, defined as $\pi_{h}=p_{m}-p$, must exist if the bidder benefits from an acquisition $(\lambda<1)$ and the bid has an equity portion $(e>0)$.

$$
\lambda>0 \wedge e>0 \rightarrow \pi_{h}=p_{m}-p=\frac{e b}{v_{f}^{T}}\left(\frac{v_{f}^{T}+s-b}{v_{f}^{B}+e b}\right)>0
$$

Lemma 1 indicates that hidden earnouts cannot be included in the offer premium explicitly. This is the crucial difference between equity-based and cash earnouts. The latter are future cash payments contingent upon some observable measure of performance. Cash earnouts have no hidden component and can be fully integrated into the offer premium, either with their maximum amount (e.g., SDC bid data) or their expected value.

Hidden earnouts can be so large that a bid below fair market value $(p<0)$ still allows for substantial post-merger gains for target shareholders resulting in a positive post-merger premium $\left(p_{m}>0\right)$. Proposition 1 determines a necessary and sufficient condition for negative premiums.

Proposition 1. Hidden Earnouts and Negative Premiums: A negative offer premium $(p<0)$ results in a positive post-merger premium $\left(p_{m}>0\right)$ if hidden earnouts are sufficiently high. Hidden earnouts are sufficient if and only if the following inequality holds. 


$$
\frac{s}{v_{f}^{B}}>\frac{1}{e}\left(\frac{-p}{1+p}\right), e>0
$$

Proposition 1 indicates that target shareholders accept a negative premium if synergies relative to the bidder's fundamental value are sufficient. Increasing the equity portion $(e)$ of the bid makes fulfilling this requirement easier, which we test empirically.

The question remains as to why merger parties would entertain an offer with such a high portion of hidden earnouts that the offer premium turns negative. Even a very friendly target with a weak negotiation position should be able to trade off some hidden earnouts for a slim positive offer premium. However, the relative size of the target plays a crucial role. Imagine the extreme case where a target's fair market value exceeds the bidder's value. Here, the only available solution to pay with bidder shares without losing majority control is a negative premium, derived in Proposition 2. Empirically, we expect a positive relation between relative target size and the likelihood of negative premiums.

Proposition 2. Control: If bidders need to finance an acquisition with an equity portion ( $e>0)$ and want to control the merged entity $(\xi<0.5)$, a negative premium with sufficient hidden earnouts is the only possibility if the target is large.

$$
e>0 \wedge \delta^{T}=0 \wedge \xi<0.5 \wedge v_{f}^{T}>\frac{v_{f}^{B}}{e} \rightarrow p<0
$$


To develop Proposition 3 on the market reaction to negative premiums with hidden earnouts, recall that hidden earnouts cannot be included in the bid explicitly.

Proposition 3. Market Response to Hidden Earnouts: Hidden earnouts $\left(\pi_{h}\right)$ cannot be reflected in the offer premium (p) based on Lemma 1. Thus, hidden earnouts trigger a positive announcement return of the target's shares in the magnitude of hidden earnouts.

\section{Target Overvaluation $\left(v^{T}>b\right)$}

If the target is overvalued, its stand-alone value exceeds the initial bid $\left(v^{T}=v_{f}^{T}+\delta^{T}>\right.$ b) leading to a negative premium by Equation (1). The target shareholders accept a negative premium only if the post-merger premium is strictly positive $\left(p_{m}>0\right)$ summarized in Proposition 4.

Proposition 4. Overvaluation: If a target is overvalued so that $v^{T}=v_{f}^{T}+\delta^{T}>b, a$ negative offer premium $(p<0)$ results in a positive post-merger premium $\left(p_{m}>0\right)$ if the following inequality holds.

$$
b=\lambda s+v_{f}^{T}>\frac{v_{f}^{B} v_{f}^{T}}{e s+v_{f}^{B}}
$$

A cash merger $(e=0)$ fulfills this inequality if $s>0$ and $\lambda>0$. An increase in the equity portion of the bid $(e>0)$ allows a lower initial bid that still fulfills the inequality due to hidden earnouts. 
The question remains as to why the target management would accept the disclosure of the overvaluation with the announcement of a negative premium (A-4). One reason could be that the overvaluation will soon become public knowledge, as in the case of CNT (see the introduction). If this coincides with pre-announcement merger negotiations, the target's management may prefer to announce a negative premium than an overvaluation that leads to an even lower (fair) stand-alone value.

In addition to fundamental overvaluation, forecasting errors in pre-bid run-ups can produce speculative overvaluation. Run-ups can reflect takeover anticipation based on diverse information, such as other mergers in the same industry or rumors (Eckbo, 2009; Jarrell and Poulsen, 1989). According to this view, referred to as the substitution hypothesis, run-ups partially substitute the premium by anticipating some portion of the target's synergies (Eckbo, 2009; Jarrell and Poulsen, 1989). ${ }^{5}$ Recently, Betton et al. (2014) provided strong evidence in favor of the substitution hypothesis. Thus, even if run-ups do not fully substitute post-merger premiums, on average, the upper tail of the distribution may over-anticipate synergies causing negative premiums.

\section{Proposition 5. Run-ups: If run-ups substitute and overestimate the target's share} of future synergies so that $E(\lambda s)>\lambda s$, then a fair bid $b=v_{f}^{T}+\lambda s$ results in a negative premium $p<0$.

\footnotetext{
${ }^{5}$ Alternatively, the mark up hypothesis states that run-ups contain new information about the target's fundamental value. According to this hypothesis, run-ups cannot lead to speculative overvaluation as an increase in the run-up forces the bidder to mark up the offer price accordingly (Schwert, 1996).
} 
If a target is overvalued, either fundamentally in its stand-alone value or speculatively in expected merger gains, Propositions 4 and 5 indicate that a negative premium occurs. The market will correct this overvaluation irrespective of its cause with negative abnormal announcement returns as summarized in Proposition 6.

\author{
Proposition 6. Market Response to Overvaluation and Run-ups: If a target's \\ fundamental value, $v_{f}^{T}$, or its merger gains, $\lambda s$, or both, are sufficiently \\ overestimated such that $\delta^{T}>\lambda s$ or $E(\lambda s)>\lambda s$, the target's abnormal announcement \\ return to negative premiums is negative.
}

\title{
D. Liquidity
}

In illiquid markets for corporate control, targets may have to offer a liquidity discount (Schlingemann et al., 2002). For negative premiums, liquidity discounts need to be substantial. This is the case when targets are forced to sell because they are financially distressed or face (imminent) bankruptcy, as in fire sales (Shleifer and Vishny, 1992). Several studies present evidence regarding fire sales with significant discounts (Pulvino, 1998; Todd, 1999; Ramey and Shapiro, 2001; Viral, Sreedhar, and Anand, 2007).

Liquidity discounts can only explain negative premiums if the post-merger premium is strictly positive. Thus, even if target shareholders are forced to sell, they still must benefit when compared to all other options. Here two assumptions come into play. First, if the target is not taken over within a certain period, its value could be even lower. As such, merger talks are often initiated by distressed targets to avoid bankruptcy or pre-emptive liquidation (Eckbo and Thorburn, 2008; Thorburn, 2000). In addition, according to Q theory (Jovanovic and 
Rousseau, 2002), assets are reallocated from low-Q sellers to high-Q buyers. If bidders can employ the same assets more efficiently, their bid should exceed the target's stand-alone alternative.

In our model, target shareholders anticipate a liquidation value of $0 \leq v_{l}^{T}<v_{f}^{T}$ as the target's ultimate value without a takeover. ${ }^{6}$ In a liquid market, a bidder is willing to pay $\mathrm{b}=v_{f}^{T}$ $+\lambda s$, but in an illiquid market, a liquidity discount $1 \in[0,1]$ can reduce the bid by more than the target's gains $(1 b>\lambda s)$ resulting in a negative premium $p=(b-1 b) / v_{f}^{T}-1$. The post-merger premium is strictly positive as target shareholders relate the discounted bid to an even lower liquidation value.

Proposition 7. Liquidity: If liquidity discounts are sufficiently high $(l>\lambda s / b)$ and targets anticipate a non-takeover value that is sufficiently low $\left(v l^{T}<b\right.$-lb), offer premiums $p=(b-l b) / v_{f}^{T}-1$ are negative, while post-merger premiums $p_{m}=b(1-$ l) $/ v_{l}^{T}$ are strictly positive.

\section{E. Agency Theory}

If the target's managers privately benefit from selling the target below its fair value, agency theory suggests that they will do so. At the announcement, we would observe a negative offer premium. However, by design, the post-merger premium would be negative as well violating target shareholders' participation constraints. Anticipating this, target managers will not support a merger below fair market value if the deal is motivated purely by selfinterest. This is different for positive premiums. Even if positive premiums are lower due to

\footnotetext{
${ }^{6}$ For simplicity, we assume a liquidation value, but target shareholders can anticipate any future stand-alone value lower than $\mathrm{v} f_{\mathrm{f}}^{\mathrm{T}}$.
} 
agency costs, shareholders will still benefit. If the post-merger premium with agency costs is positive, however, the offer premium is also positive.

However, if we assume information asymmetry, it is possible that a manager communicates non-existent synergies to shareholders to close a deal with a negative premium if it is in the manager's interest. Then, the post-merger value is positive in the eyes of the shareholders thereby fulfilling their participation constraints. It should be possible, however, to write a contract that prevents this. However, we cannot assume that this is always the case. Thus, in cases without such a contract, agency costs could potentially explain negative premiums.

The empirical evidence on positive target premiums and agency costs is mixed and type dependent. While Bargeron, Schlingemann, Stulz, and Zutter (2009) find no relation with target CEO retention, Hartzell, Ofek, and Yermack (2004) report a negative correlation with cash payments for target CEOs and Moeller (2005) notes a negative and a positive relation with target shareholder control in the 1980s and 1990s, respectively. Recently, Luypaert and Van Caneghem (2017) analyze information asymmetry, which is a prerequisite for agency costs, in the context of M\&As. They demonstrate, in a large scale study, that information asymmetry affects payment choices and acquisition gains. Yet, their main findings indicate that information asymmetry makes cash mergers more likely, and bidders benefit from opaque targets due to cash offers leaving future gains with bidders' shareholders. This mechanism is fundamentally different from our theory as negative premiums are more likely in stock mergers. 


\section{Data and Variables}

\section{A. Sample Design}

We included takeover offers announced from 1995-2011 recorded in Thomson Reuters SDC. The database provides the most reliable and accurate information on takeovers (Bollaert and Delanghe, 2015) with good coverage since the late 80's (Barnes, Harp, and Oler, 2014). ${ }^{7}$ Bids in the sample are subject to the following criteria. ${ }^{8}$ The deal value exceeds 10 million USD. Bidders had no toehold and made an offer for $100 \%$ of the target's shares. Both companies were incorporated in the U.S. and had common shares covered by Datastream. The deal is not pending and was either completed or officially withdrawn until the end of 2015 . To reduce the influence of regulation, we removed financial firms (SIC 6000-6999) and utilities (SIC 4900-4999).

We use stock prices adjusted for dividends and stock splits as both can cause negative premiums. If a target receives several bids, only the first is considered to minimize confounding events. Here, we used SDC's "original date announced," which is the very first bid in a possible sequence and the most reliable date for premium measures (Mulherin and Simsir, 2015). All acquisitions with the same immediate or ultimate parent are eliminated (e.g., internal reorganization). We also exclude partial acquisitions, asset sales, and multiple acquisitions on the same day. ${ }^{9}$ Negative premiums are also common in reverse mergers that

\footnotetext{
${ }^{7}$ We find that information on an acquirers' announced offer price for a target share is most accurate since the early 90's, which is why the sample begins in 1995.

${ }^{8}$ For studies with similar criteria see, Betton et al. (2014), Dong et al. (2006), Helwege, Pirinsky, and Stulz (2007), and Schlingemann (2004).

${ }^{9}$ Parallel asset sales can hollow out a target. Also, if several subsidiaries are purchased together, tax reasons can make it worthwhile to negotiate negative premiums for some in combination with high premiums for others.
} 
allow private companies to obtain listings without IPOs (Gleason, Rosenthal, and Wiggins, 2005). For this reason and due to data availability, we remove private targets. We also ignore mandatory offers, where a bidder is required by law to make an offer for the remaining shares of the target, as they may be artificially low. ${ }^{10}$ Finally, we exclude spinoffs, recapitalizations, self-tenders, repurchases, deals with a state controlled entity, and deals with estimated announcement dates.

After this procedure, we manually check stock prices, announcement dates, and SEC merger filings of all targets with negative premiums without uncovering any other technical, legal, or tax-related explanations. The final sample consists of 1,937 deals with offer premiums in SDC. Bidders and targets in SDC are matched with Datastream using SEDOLs and CUSIPs resulting in 1,776 deals after list-wise deletion.

\section{B. Premium Measures}

The offer premium refers to the officially announced offer price per outstanding target share, as reported in SDC, divided by a base price. We use the target's share price four weeks (20 trading days, $t=-20$ ) prior to the announcement as the base price. This base price should be largely free of leakage of information and market anticipation of the pending offer.

Selecting an earlier date would minimize the inclusion of run-ups, but would also open the window for confounding events. As the correct base price is unknown (Eckbo, 2009), Section IV reports robustness checks using base prices eight weeks $(t=-40)$, one week $(t=-5)$, and one day $(t=-1)$ prior to the announcement. These windows are in line with recent studies (e.g., Betton et al., 2014 use $t=-42$ ).

\footnotetext{
${ }^{10}$ In the U.S., there is no general mandatory bid requirement, except in a few states, if the bidder's stake exceeds a certain threshold (20\% in Pennsylvania, 25\% in Maine, and 50\% in South Dakota).
} 
Following Krishnan, Hitt, and Park (2007), we adjust the base price with the change in the S\&P 500 from the reference point (e.g., $t=-20)$ to the announcement $(t=0)$. Marketadjusted premiums control for negative premiums due to adverse market movements, where the valuation of the whole market, and not only of the target, drops. We also compute a premium measure without index correction. Empirically, the differences are negligible (see Section IV). Based on the four-week measure $(t=-20)$, the number of negative premiums increases from 154 to 162 after adjusting for stock market movement. Except when stated otherwise, our models refer to the four-week premium $(t=-20)$ adjusted for changes in the S\&P 500.

From the bidder's perspective, the total consideration paid for the target is often higher than the equity price received by the target shareholders. Next to capital infusions and liabilities assumed, the total consideration also includes, among others, the purchase of options, assets, and warrants. However, we are interested in the perspective of ordinary target shareholders and why they accept negative premiums. Thus, we refrain from using the total consideration to prevent mixed perspectives in our analysis.

\section{Construction of Variables}

To test Proposition 1, we use the equity portion of the bid (EQ) from SDC and compute proxies for hidden earnouts. Hidden earnouts increase in synergies, which are unobserved. We use the bidders cumulated abnormal return around the announcement (CAR $B$ ) as one proxy, defined as the market adjusted $C A R$ from $t=-1$ to $t=1$ (Dong et al., 2006). ${ }^{11}$ Other imperfect proxies for synergies include the target's operational profitability $(R O I C)$,

\footnotetext{
${ }^{11}$ We compute $C A R T$ analogously.
} 
cost-income ratio $(C I)$, and capital turnover (TURNOVER). ${ }^{12}$ More importantly, we also compute a direct measure of hidden earnouts $(H E)$, which is based on the theoretical value derived in Lemma 1. In doing so, we replace unobserved fundamental values with postannouncement market values at $t=5$, which should reflect expected synergies and adjustments for mispricing.

Section IV considers alternative windows to capture the market response measured by cumulated abnormal returns $(C A R B$ and $C A R T)$. Apparently, windows that are too short may limit the market in fully understanding and compounding expected synergies into the price. Yet, extending the window reduces the sample and introduces an attrition bias toward mergers that take longer to conclude.

Proposition 2 suggests that the target's size matters. We include relative size (RSIZE), defined as the ratio of the target over bidder market capitalization at $t=-20$, and a dummy (BIG T) for the upper quintile of relative size. Although we exclude reverse mergers, some bidders issue more than half of their equity as the consideration paid often exceeds the equity price received by the target shareholders. Thus, even if bidders issue more than half of their post-issuance equity (e.g., for cash injections), it is not a given that they transfer control to the target shareholders. The latter, however, indirectly benefit via hidden earnouts. A dummy controls for these mergers (NEWEQ50) as indicated in SDC.

To test Proposition 3, we measure the market response to hidden earnouts with postannouncement premiums (PAPs) as explained in Section III C). PAPs are defined as the target's share price after the announcement divided by the announced value of the bid. We use

${ }^{12} R O I C$ is earnings before interest and taxes over fixed assets, $C I$ refers to operating costs over revenues, and TURNOVER is revenues over fixed assets. 
market-adjusted premiums with a base price at $t=5$ (see Section II B). Five trading days should suffice to capture the market's response, while limiting confounding events.

To test Proposition 4, we include Tobin's $\mathrm{Q}(T Q T, T Q B)$, defined as the ratio of the market value of assets over the book value of assets at $t=-20$. As in Masulis, Wang, and Xie (2007), the market value of assets refers to the book value of assets minus the book value of common equity plus the market value of common equity. Tobin's $\mathrm{Q}$ is an overall measure, which does not reveal the underlying reason for overvaluation. To identify firm (FIRMT, FIRM B), sector (SECTOR T, SECTOR B) and long run overvaluation ( $L O N G T, L O N G B)$, we apply the decomposition developed by Rhodes-Kropf, Robinson, and Viswanathan (2005) based on constituents of the S\&P 500. Updating constituents annually from 1995-2011 avoids a survivorship bias. Following Rhodes-Kropf et al. (2005), we regress the value of equity, $m_{i t}$, of firm $i$ in year $t$ on the book value of equity, $b_{i t}$. Coefficients $\alpha_{0 j t}$ and $\alpha_{1 j t}$ vary over time and industry $j$ using the 12 Fama-French (1997) industries.

$$
m_{i t}=\alpha_{0 j t}+\alpha_{1 j t} b_{i t}+\varepsilon_{i t}
$$

Equation (6) constitutes a benchmarking exercise, where market valuation is related to a firm's fundamentals, industry, and time-specific effects. Firm-specific errors refer to the observed market value of equity minus the predicted value given a firm's fundamentals, where coefficients vary over time and across industries. Sector related waves in overvaluation are equal to the difference in predicted valuations with varying time-industry coefficients and predictions based on time averages. ${ }^{13}$ The difference between predicted valuation based on

\footnotetext{
${ }^{13}$ Coefficients in Equation (6) are averaged over time such that $\bar{\alpha}_{1 j}=\frac{1}{T} \sum_{t=1}^{T} \alpha_{1 j t}$.
} 
time averages and actual fundamentals determines the long run component, which reflects a firm's long run growth potential. Accordingly, firm and sector overvaluation are related to Proposition 4, while long run overvaluation can be regarded as a proxy for future growth potential and synergies, essential in Proposition 1.

To test Proposition 5, we compute the S\&P 500-adjusted buy and hold returns to the target from $t=-20$ to $t=-1$ as run-ups $(R U N U P)$ in line with windows suggested by Schwert (1996) and Betton, Eckbo, and Thorburn (2009). To assess Proposition 7, we follow Shleifer and Vishny (1992) and determine the monthly M\&A volume (MKT VOL) and the number of transactions $(M K T$ BIDS) in an industry based on the two-digit SIC codes of the targets (Schlingemann et al., 2002). We also capture a target's financial health using leverage defined as total debt to equity ( $L E V E R A G E)$, the ratio of short-term debt to long-term debt (SHORT $D E B T)$, cash and cash equivalents to total assets $(C A S H T A)$, and working capital relative to total assets $(W C T A)$.

In line with Eckbo (2009), dummies account for tender offers (TENDER) and hostile bids (HOSTILE). As the first bid may put a target into play, we control for pre-emptive bidding with high initial premiums by including a dummy for multiple bids (NUMBID) (Fishman, 1988). Analogously, we control for withdrawn bids, which may be due to low premiums (WITHDRAWN). Horizontal mergers (HORIZONTAL), defined as matching fourdigit SIC codes, may differ in terms of synergy potential, but also because both parties may be jointly affected by industry-specific factors, such as industry debt overhang (Clayton and Ravid, 2002) or wider financial distress, which can be contagious within an industry (Lang and Stulz, 1992). All accounting-based measures refer to the latest available annual data prior to the bid. Section IV introduces additional measures for robustness checks and extensions. 


\section{Empirical Analysis}

\section{A. Descriptive Findings}

Using our standard premium measure (see Section II B), Table II reports the average premium is $43.2 \%$, comparable to other samples (Betton et al., 2014). The 25 th percentile (p25) of all premiums is positive in all years with a mean of $18.5 \% .{ }^{14}$ On average, $8.4 \%$ of all transactions from 1995-2011 had a negative premium (NEG) with a maximum (minimum) share of $14.1 \%(2.3 \%)$ in 2002 (2006). Negative premiums are not marginal errors just below zero. Their average size is $-15.5 \%$, ranging from $-5.1 \%$ in 2006 to $-27.6 \%$ in $2008 .{ }^{15}$ Table II also presents the market response to negative premiums based on cumulative abnormal returns to the target (CARs) and post-announcement premiums (PAPs, with a base price at $t=5$ ). Negative and positive market reactions are rather balanced with 85 (77) positive and $73(85)$ negative PAPs (CARs) with fluctuations over time. This supports Propositions 3 and 6 that the market responds differently to negative premiums depending upon the underlying cause.

Insert Table II about here.

Figures 1 and 2 illustrate the development of daily premiums, defined by the targets' daily stock prices over their announced bids, and target and bidder CARs for mergers where

\footnotetext{
14 The 25th percentile defines low premiums in Section V.

${ }^{15}$ See Section $\mathrm{V}$ for an international comparison of negative premiums.
} 
our standard premium measure is negative. A cursory inspection of Figure 1 (for mergers with a negative PAP) reveals that the daily premium stays consistently negative, while target CARs react positively to negative premium announcements indicating hidden earnouts. Negative premiums that increase to positive PAPs (see Figure 2) are accompanied by a sharp drop in target CARs indicating a correction of overvaluation.

Insert Figures 1 and 2 about here.

Table III provides the descriptive statistics. In line with the literature (Dong et al., 2006), we winsorized all variables at the 1st and 99th percentile, which does not affect the incidence of negative premiums, as the lowest percentile is negative.

Insert Table III about here.

\section{B. Determinants of Negative Premiums}

Logistic regressions model the binary outcome of a negative premium. ${ }^{16}$ Specifying the reference Model (A) in Table IV requires a trade-off between the discriminatory power of covariates and the number of observations. To assess discriminatory power, we conduct logistic models with each covariate separately. We select covariates with the largest area under the receiver operating characteristic (ROC) curve with a minimum of 1,776 observations. All models account for: 1) industry-specific effects by including dummies for the target's and the

\footnotetext{
${ }^{16}$ Probit specifications provide similar results.
} 
bidder's SIC code and 2) year dummies. All standard errors are adjusted for heteroskedasticity using the Huber-White (1980) sandwich estimator.

Table IV reports the reference Model (A), which identifies the main drivers of negative premiums: 1) targets with high Tobin's $\mathrm{Q}(T Q T), 2)$ bidders with low Tobin's $\mathrm{Q}(T Q B), 3)$ deals with a large equity portion $(E Q), 4)$ relatively large targets $(R S I Z E)$, and 5) industries with low M\&A transaction volume (MKT VOL). The equity portion of the bid makes hidden earnouts more likely as stated by Proposition 1. Relative size is a proxy for the importance of synergies and control, demonstrated by Proposition 2. Overvalued targets exhibit more negative premiums in line with Proposition 4. Finally, there is evidence in support of Proposition 7 as industries with low M\&A volume exhibit a higher proportion of negative premiums.

To identify the cause of overvaluation, we decompose valuation levels into firm, sector, and long run components. The three components for bidders and targets are correlated as bidders with high long run growth potential selecting similar targets. Thus, Model (B) uses the target's components, while Model (C) includes the bidder's components separately to avoid multicollinearity. By construction, decomposition accounts for market movement. Therefore, we use the premium measure without index correction (see Section II B). Models (B) and (C) indicate that long run growth potential makes negative premiums more likely suggesting that hidden earnouts may play a role. This notion is corroborated by the fact that less growth-driven, short run overvaluation (firm- and sector-specific) primarily predicts premiums that are low, but not necessarily negative. Model (D) includes the direct measure of hidden earnouts $(H E)$, which has a highly significant positive impact on the occurrence of negative premiums. Moreover, Model (D) accounts for large targets using the dummy BIG T. 
All partial impacts identified by Model (A) remain in place. In addition, equity issues in excess of $50 \%$ of the bidder's market value indicate a significant effect providing further support for Proposition 2. Model (E) explores the target's profitability (ROIC), cost efficiency $(C I)$, and asset utilization (TURNOVER), which could indicate synergy potential. These accounting measures greatly reduce the number of observations and lack explanatory power.

To test whether targets with financial constraints are more susceptible to negative premiums, Specification (F) adds financial measures. Interestingly, targets with low leverage (LEVERAGE) and low working capital (WC TA) are more likely to exhibit negative premiums undermining the fire sales hypothesis and Proposition 7. SDC also provides a dummy flagging targets that go bankrupt during the transaction and the amount of capital infusion into the target during the transaction (normalized over the target's market value at $t=-20$ ). Both variables are dropped from the estimation as they perfectly predict positive premiums, contradicting Proposition 7. Section IV considers additional measures for financial constraints, distress, and stock market liquidity.

Insert Table IV about here.

To test Proposition 5, we use a premium measure with a base price at $t=-1$ so that the measurement periods for run-ups $(t=-20$ to $t=-1)$ and premiums do not overlap. Table $\mathrm{V}$ reports the reference Model (A) using a base price at $t=-1$ in Column (G). In support of Proposition 5, Column $(\mathrm{H})$ indicates that run-ups have a positive impact on the likelihood of negative premiums. 
It is not clear, however, whether run-ups reflect an overvaluation of the target's fundamental value or an overestimation of expected merger gains for the target. In a first step, we control for the decomposed valuation levels in Columns (I) and (J). If run-ups only reflect fundamental overvaluation, we would expect to see no effect of run-ups and a positive and significant impact of FIRM T or SECTOR T. We find that the predictive power of run-ups for short-term negative premiums remains intact. In a second step, we include the interaction term between run-ups and Tobin's $\mathrm{Q}(R U N U P x T Q T)$ in Column (K). If run-ups merely reflect an increase in Tobin's Q, the interaction term would be positive. However, in support of Proposition 5, the interaction term is negative and significant. Moreover, Column (L) considers the interaction between run-ups and the M\&A transaction volume in the industry (RUNUPxVOL) revealing a positive coefficient. Industries with high M\&A activity and high run-ups lead to negative premiums due to overstated takeover expectations, as the market seems to anticipate further bids in the industry. Accordingly, run-ups capture an overshooting of takeover expectations, which differs from the overvaluation of a target's stand-alone value.

Insert Table $\mathrm{V}$ about here.

\section{Market Reaction to Negative Premiums}

Following Amemiya (1985) and Liao (1994), we specify sequential logistic models for two steps: 1) whether a premium is positive or negative and 2) how the market responds to negative premiums. The logistic models presented thus far address the first step, isolating overvaluation and hidden earnouts as the most promising explanations. The second step 
focuses on these explanations. Propositions 3 and 6 also provide theoretical predictions regarding discriminating market reactions to negative premiums.

To test Proposition 3, we need to stress that hidden earnouts are present in all stock mergers (Lemma 1). This increases the chance that the announcement return to hidden earnouts is confounded with possible effects of target overvaluation. Overvalued targets trigger a negative announcement return, which can overcompensate for the positive announcement effect of hidden earnouts. ${ }^{17}$ Thus, although negative announcement returns can reliably identify overvaluation in negative premiums (see Section I C), they partially hide hidden earnouts.

While overvalued stock mergers always have hidden earnouts, mergers with hidden earnouts are not always overvalued. We can distinguish the positive effects of hidden earnouts from the negative effects of overvaluation by benchmarking the market reaction to the bid, as in the post-announcement premium (PAP). The PAP refers to the target's share price shortly after the announcement at $t=5$ divided by the value of the bid. The PAP clearly identifies cases where the post-announcement value of the target: 1) exceeds the bid due to hidden earnouts or 2) does not exceed the bid due to the absence of hidden earnouts.

The positive announcement returns of the target's shares suggested by Proposition 3 imply that the post-announcement premium (PAP) remains negative as the anticipation of hidden earnouts should prevent the target's price adjustment from hitting or undercutting the bid price. In fact, as indicated below, the average target return $(C A R T)$ is positive when premiums stay negative after their announcement. This indicates that PAPs successfully

\footnotetext{
${ }^{17}$ Suppose a target with a market capitalization of 100 and a fair value of 80 accepts a stock-for-stock bid of 90 with hidden earnouts of five. The offer premium is negative $[90 /(80+20)-1]$, the post-merger premium is positive $[(90+5) / 80-1]$, but the target's announcement return is negative as the market capitalization falls from 100 to 95 .
} 
identify hidden earnouts. Thus, the dependent variable takes a value of one for negative PAPs and zero otherwise. This estimation procedure corresponds to the previous section.

Table VI underscores the notion that the signs of the coefficients of the target's and the bidder's Tobin's Q change compared to Tables IV and V indicating that PAPs distinguish between hidden earnouts and overvaluation. Column (M) reports that bidders with high valuation $(T Q B)$ exhibit a market reaction in line with hidden earnouts. This is consistent with the Q theory of mergers (Jovanovic and Rousseau, 2002). However, decomposing valuation levels in Columns $(\mathrm{N})$ and $(\mathrm{O})$ do not confirm these findings. Columns $(\mathrm{P})$ and $(\mathrm{Q})$ add the direct measure of hidden earnouts $(H E)$, which has explanatory power. In addition, Column (Q) provides robustness to the inclusion of abnormal returns $(C A R T, C A R B)$ and demonstrates that the market reacts positively to the announcement of negative premiums when they expect hidden earnouts. Positive CARs for both the targets and the bidders can also be interpreted as proxies of high expected synergies.

In Columns $(\mathrm{P}),(\mathrm{Q})$, and $(\mathrm{R})$, the dummy for large targets $(B I G T)$ and the interaction term between large targets and the equity portion of the bid (EQxBIG T) clearly identify hidden earnouts. Based on these two coefficients, it is evident that a target needs to be large and the deal requires a substantial equity portion to observe the market reaction expected from hidden earnouts.

Most specifications indicate that horizontal mergers are associated with hidden earnouts, consistent with the view that these mergers promise higher synergies. Finally, Column (R) includes run-ups and confirms that speculative overvaluation cannot explain a market reaction consistent with hidden earnouts. 
These findings support Proposition 3 and correspond to our findings in the first step (Tables IV and V). There is, however, one striking exception. Although the equity portion $(E Q)$ is a strong and consistent predictor of negative premiums, it fails to discriminate between hidden earnouts and overvaluation as the underlying cause except in combination with large targets $(E Q x B I G T)$. Previous studies find that higher target valuations are associated with a greater likelihood of all-equity bids and with lower premiums (Dong et al., 2006; Betton et al., 2008). Our results are in line with these findings. If equity bids are more likely for deals with high target (mis)valuations, as well as high hidden earnouts, the equity portion cannot distinguish between the two underlying reasons for negative premiums. The combination of a high equity portion and a large target, however, leads to hidden earnouts in line with Proposition 2.

Insert Table VI about here.

Proposition 6 states that the announcement of a negative premium due to overvaluation should trigger negative target abnormal returns. As only the sign of this reaction matters, our sequential logistic models use a binary dependent variable that distinguishes between a negative abnormal return $(1$ if $C A R T<0)$ and a non-negative return ( 0 if $C A R T \geq 0)$. Table VII reports the basic Specification (S), replacing Tobin's Q with decomposed valuation levels in Specifications (T) and (U), adding run-ups in Specification (V), the interaction effect between run-ups and the target's valuation in Specification (W), the direct measure of hidden earnouts in Specification (X), and the bidder's abnormal market response, as well as proxies for liquidity in Specification (Y). 
The dummy for hostile takeovers is omitted since all negative premiums with a negative market response refer to friendly deals. All of the specifications indicate that a negative market response is more likely if the target is overvalued (TQ T) or the market overstates the target's gain from mergers captured by run-ups (RUNUP) and the interaction term (RUNUPXTQ T). Specification (T) reveals that firm- and sector-specific overvaluation (FIRM T, SECTOR T) explains a negative market response, thus supporting Proposition 6. Neither the proxies for hidden earnouts $(E Q, R S I Z E)$ nor the direct measure $(H E)$ are significant in the second step supporting our notion that negative premiums with a negative abnormal return are due to overvaluation. ${ }^{18}$

Run-ups not only predict negative premiums (see Table V), but also a downward market correction (see Specifications (V)-(Y) in Table VII). Taking these two findings together, we can infer that excessive run-ups are neither a mere symptom of hidden earnouts nor of fundamental overvaluation, but constitute a reason for negative premiums in their own right. This is in line with Ang and Ismail (2015). Specification (Y) demonstrates that the effect of run-ups is also robust to the inclusion of the market reaction to the bidder. A greater likelihood for a negative market response is associated with a lower $C A R B$ indicating that bidder shareholders are skeptical about deals where target overvaluation may be the reason for negative premiums. Specification (Y) tests liquidity as a competing explanation, but without support.

\footnotetext{
${ }^{18}$ For robustness, we also used a propensity score matching approach, where we compare matched samples of the targets with similar valuation levels (and other characteristics) prior to the merger announcements and compare their market responses after the announcement. The results corroborate our findings above. We find that the observed target market responses are caused by hidden earnouts or overvaluation events and not by the targets' characteristics as the matched sample (i.e., targets with similar characteristics) exhibits a distinctly different market response. Details regarding the methodology and results are available from the authors upon request.
} 
Insert Table VII about here.

\section{Robustness and Extensions}

\section{A. Alternative Measures of Premiums}

We re-estimate our models for different premium measures, which vary in terms of base price and market adjustments discussed in Section II B. Table W1 in the Web Appendix B reports the reference $\operatorname{Model}(\mathrm{A})$ for six alternative premium measures. (R1) refers to our standard base price at $t=-20$, but excludes slightly negative premiums, which may be due to noise, by coding negative premiums that are smaller than $-5 \%$ with a dummy equal to one. (R2) refers to our standard base price at $t=-20$, but without adjusting for changes in the S\&P 500 Index. (R3) and (R4) compute index-adjusted premiums with a base price at $t=-5$ and $t=$ -1 , respectively. (R5) refers to the average of the index-adjusted target share prices at $t=-20, t$ $=-5$, and $t=-1$. Finally, (R6) applies an index-adjusted base price at $t=-40$. Our results do not depend on the premium measure.

\section{B. Cash Mergers and Multiple Bids}

Negative premiums exhibit a high equity portion $(E Q)$. However, we stress that 23 negative premiums occur in cash mergers. Thus, the method of payment is not a guarantee for observing positive premiums. To account for the possibility that other factors affect the method of payment as outlined in Eckbo (2009), Table W2 in the Web Appendix B shows our reference Models (A) and (B) excluding cash mergers in (R7) and (R8), respectively. Apparently, our results are robust. Finally, (R9) and (R10) remove multiple bids stressing that the number of bids does not affect our findings. 


\section{Other Control Variables}

In unreported robustness checks, we also test the following control variables from SDC: 1) cash infusion into the target, 2) bankruptcy of the target, 3) cash earnouts in percent of the bid price, 4) a dummy for shareholder litigation, 5) termination fees, 6) lockup options, and 7) for collars. ${ }^{19}$ The results reported in this paper remain qualitatively unchanged. As explained in Section III B, some of these controls lack the necessary variation for inclusion in the reference model.

\section{Extension to Stock Liquidity and Other Proxies of Financial Health}

Next to liquidity discounts in the market for corporate control, low liquidity in the stock market can also affect negative premiums. If a target's stock is rarely traded, its price is less likely to correct for a possible overvaluation in a timely manner. As explained in Section I, this can lead to negative premiums. Moreover, M\&As can present discounted exit opportunities if the target's stocks are illiquid (Greenwood and Schor, 2009).

As tick data is not available for many targets in our sample, we construct measures based on daily closing prices from $t=-250$ to $t=10$. We estimate the effective bid-ask spread based on the covariance of subsequent changes in closing prices (SPREAD) and the proportion of days per month with zero returns (ZERO) as defined in Roll (1984) and Lesmond, Ogden, and Trzcinka (1999), respectively.

${ }^{19}$ Collars define floors and/or caps for bidder stock prices within which the exchange ratio is fixed (Officer, 2004, 2006). In our model, a collar breach constitutes a new bid. In a new bid, initially negative premiums can become positive and vice versa. For negative premiums in the initial, focal bid, however, collars do not affect our findings. Analogously, this also applies to termination fees and lockup options if executed. 
We also compute and test alternative proxies for a target's financial health including Altman's Z-score (Z SCORE), a dummy for distressed targets based on a Z-score below 1.23 (Z DISS) (Altman, Haldeman, and Narayanan, 1977), and the $W W$ index for financial constraints (Whited and $\mathrm{Wu}, 2006$ ). The $W W$ index is a linear combination of cash flow to total assets, sales growth, long-term debt to total assets, the log of total assets, dividend policy indicators, and industry sales growth.

Table W3 in the Web Appendix B presents the results for stock market liquidity in (E1) measured by SPREAD and ZERO. Both do not explain negative premiums. (E2) includes $Z$ DISS and (E3) contains Altman's Z SCORE. Both measures of financial distress do not have explanatory power. Finally, (E4) incorporates $W W$, which is significant and positive, highlighting that financially constrained targets are more likely to accept negative premiums. Note, however, that the inclusion of $W W, Z D I S S$, and $Z S C O R E$ results in a considerable loss of cases. Overall, the results provide only weak evidence for market liquidity and financial distress.

\section{E. Extension to Low Premiums (LPs)}

Negative premiums are the most extreme and distinctive outcome of the much larger phenomenon of low premiums (LPs), defined as the lowest quartile of all premiums. Most LPs are non-negative premiums (see Table II). Note that LPs include sizeable, positive premiums. The premium at the 25 th percentile is $18.5 \%$.

The same theory that explains negative premiums also generalizes to LPs as hidden earnouts, overvaluation, and liquidity effects potentially always exist, diminishing premiums in general. Accordingly, all propositions in Section I also apply to lower premiums. 
To test this conjecture, we rerun the estimations in Table IV with dummies for LPs as the dependent variable. Table W4 in Web Appendix B reports the results. The main findings, including the positive impact of the target's valuation ( $T Q T)$, equity portion $(E Q)$, relative size (RSIZE, the measure of hidden earnouts $(H E)$, and the negative impact of market volume (MKT VOL), are not affected by the inclusion of low positive premiums. In fact, a target's overvaluation, as measured by decomposed valuation levels in (E6) and (E7), seems to be a stronger predictor for LPs than for negative premiums. Overall, the results provide evidence that the proposed mechanisms behind negative premiums generalize to at least $25 \%$ of all premiums.

\section{F. Extension across Samples}

To derive a clean sample of offer premiums, we focus on a subset of U.S. American domestic takeovers after excluding a number of counterfactuals (see Section II A). The question arises to which extent our results generalize to other takeover markets and what role possible counterfactuals play. Table VIII reports the occurrence and size of negative premiums across three regional samples and for different types of deals, targets, and counterfactuals. To compile Table VIII, we did not conduct the manual checking procedure. We only accounted for the most important measurement errors, as shown in Table VIII, such as self-dealing as reported in the SDC. This approach is acceptable for providing a descriptive overview, but not sufficient for deriving a "clean sample" as outlined in Section II A. Negative premiums are clearly a worldwide phenomenon. There is little variation across regions in frequency and magnitude. North America, including Canada $(A M)$, has slightly fewer negative premiums than Europe $(E U)$ and the Asia-Pacific, including Japan $(A P)$, but 
there is virtually no difference in the median size of the negative premiums. ${ }^{20}$ The upper panel of Table VIII (WHOLE SAMPLE) reports the most prominent counterfactuals for negative premiums: 1) self-dealing (mainly mergers with the same ultimate parent), 2) bidders with toeholds, 3) mandatory bids, and 4) reverse mergers. These counterfactuals play a more important role in $E U$ and $A P$ than in $A M$. The lower panel of Table VIII (SUBSAMPLE) reports a break up for the most prominent types of deals and targets after excluding counterfactuals. In line with the results from our analyses, deals with full payment in STOCK $(\mathrm{CASH})$ clearly have a higher (lower) proportion of negative premiums across all three regions. This also applies, but to a lesser extent, to WITHDRAWN bids and HORIZONTAL targets. HOSTILE and TENDER offers and CROSSBORDER targets receive fewer bids with negative premiums across all regions, while the number of bidding competition (NUMBID) does not seem to play a distinct role. Overall, the pattern of relative importance of deal and target types for negative premiums is quite similar across regions.

Insert Table VIII about here.

\section{G. Alternative Windows for Cumulated Abnormal Returns}

Assessing the market response to hidden earnouts, Specification (Q) in Table VI relies on a standard window from $t=-1$ to $t=1$ in line with Dong et al. (2006), which might be too short to capture the market response to hidden earnouts. Thus, Table W5 in Web Appendix B reports alternative windows for the bidder's and the target's cumulated abnormal returns based on $[-1,5]$ in $\mathrm{E}(11),[-1,20]$ in $\mathrm{E}(12)$, and $[-1,60]$ in $\mathrm{E}(13)$ (i.e., until five, 20, or 60 days after

\footnotetext{
${ }^{20}$ Depending upon the sample, the median lies between $-10.5 \%$ and $-12.4 \%$ or between $-9.6 \%$ and $-11.6 \%$.
} 
the announcement). Positive target cumulated abnormal returns significantly predict negative PAPs throughout all of the windows. This corroborates the notion that hidden earnouts are at work, which are reflected in consistently higher target prices (relative to the announced bids) as the expected synergies are compounded in the market price (but not or only partly in the announced bid). This can also be seen in Figure 1. Interestingly, the market seems to adjust the bidder's share price quickly and in the short run, but not structurally, as only the window $[-1,1]$ has a significant impact. This is not against expectations as the hidden earnouts accrue to the target only, while the bidder gives up expected synergies in return for a lower price today. In the short run, bidder shareholders might value the fact that both merger parties apparently expect substantial synergies (so that hidden earnouts and negative premiums are an option) or that the bidder takes less risk in anticipated synergies (by paying a lower price), but this effect is, all else being equal, not very strong.

\section{H. Alternative Proxies of Overvaluation}

Apart from Tobin's Q and its decomposed components, we consider alternative measures suggested in the pertinent literature. Despite decomposition, it is still possible that a high Q can suggest overvaluation and/or high expectations concerning future growth and profitability, as implied by Q-theory in Jovanovic and Rousseau (2002). In line with Dong et al. (2006), we use the price-to-residual income model value (PRIMV) to capture overvaluation. The PRIMV refers to the Ohlson model and is usually based on earnings forecasts (Ohlson, 1995). Dong et al. (2006) use I/B/E/S data to obtain analysts' consensus earnings forecasts. Analysts' forecasts are not available for most targets. Thus, we use actual earnings and not forecasts to construct the price-to-residual income model value. Dong et al. (2006) determine 
the cost of equity using a market model to estimate beta. Yet, they admit substantial variation in their estimates, which they resolve with winsorization. Even after winsorization, estimates for cost of equity lead to extreme fundamental values, as estimates vary between $3 \%$ and $30 \%$. To avoid outliers, we follow D'Mello and Shroff (2000) and use a constant discount rate of 12.5\%. Furthermore, in line with Dong et al. (2006), the computation refers to a three-year window.

Based on the functional fixation hypothesis, firms with high accruals and net operating assets tend to be overvalued as investors overstate accounting performance (Hirshleifer, Hou, Teoh, and Zhang, 2004; Sloan, 1996). Thus, for robustness, we also compute operating accruals $(A C C R)$ and net operating assets $(N O A)$ as discussed in Hirshleifer et al. (2004). Unfortunately, quarterly accounting data do not cover the whole investigation period. Therefore, all accounting-related measures, including $A C C R$ and $N O A$, use the latest available annual data prior to the bid announcement. Due to the high demands on the data, however, these alternative proxies reduced the sample size from 1,767 in the reference Model (A) to 617 in Model (E14), 694 in Model (E15), and 587 in Model (E16), respectively (see Table W6). Note that only PRIMV T is significant in Model (E16). The significant reduction in the sample limits the usefulness of alternative proxies. Moreover, these measures are also affected by growth expectations, which could manifest themselves as overvaluation. Accordingly, our decomposition approach based on the readily available Tobin's Q seems to be a better approach.

\section{Agency Theory and Negative Premiums}


Theoretically, we argue that agency costs cannot explain negative premiums in the absence of information asymmetries. In practice, this is unlikely to hold. Thus, our empirical analysis considers the impact of agency costs and information asymmetry on negative premiums. As with hidden earnouts and synergies, agency costs are notoriously difficult to measure. We acknowledge that the results must be interpreted with great care, particularly as data limitations restrict us to small samples. The recent study by Luypaert and Van Caneghem (2017) uses analysts' forecasts and media coverage, which is not available for most of our targets. Thus, we have to rely on alternative proxies. Model (E) in Table IV uses measures, such as $C A S H T A, R O I C$ and $C I$, which can be interpreted as proxies for agency costs related to Jensen's (1986) Free Cash Flow Hypothesis and efficiency. Yet, the same measures can also influence synergies and are, at best, an indirect measure of agency costs.

A more direct measure refers to current discretionary accruals, which can be regarded as a proxy for managerial discretion based on agency theory (Sawicki and Shrestha, 2008, 2012). We decompose accruals into nondiscretionary accruals, $N D A$, and discretionary accruals, $D A$, by estimating a modified Jones model (Dechow, Sloan, and Sweeney, 1995). We run the following fixed effects model to determine non-discretionary accruals, where $T A$ refers to total assets, $R e v$ indicates sales, and $N R$ stands for net receivables.

$$
\operatorname{accruals}_{i t}=\alpha_{i}+\beta \frac{1}{T} A_{i t}+\gamma \frac{\Delta \operatorname{Rev}_{i t}-\Delta N R_{i t}}{T A_{i t}}+\varepsilon_{i t}
$$

The residuals of Regression (7) are discretionary accruals, while the fitted values refer to non-discretionary accruals. Table W7 reports our reference Model (A), shown in Table IV, compared to (E17), which incorporates discretionary, $D A$, and non-discretionary accruals $N D A$ 
for the targets and the acquirers. Apparently, higher discretionary accruals do not explain negative premiums.

We also account for the effect of asymmetric information using bid-ask spreads. As tick data is not available for many targets, we construct measures based on daily closing prices from $t=-250$ to $t=10$. We estimate the effective bid-ask spread based on the covariance of subsequent changes in closing prices, $S P R E A D$, as defined in Roll (1984). Empirically, effective bid-ask spreads included in Model (E18) of Table W7 do not explain the negative premiums.

(E19) extends our analysis to very low premiums (the bottom 25\%) revealing no significant partial impacts of our measures. However, in the higher quantiles (the top 25\%) shown in (E20), agency costs matter. The latter finding is interesting as it indicates that agency costs are better concealed in the case of relatively high premiums (i.e., in the top $25 \%$ of premiums). In this subgroup of mergers, high discretionary accruals lower premiums. Due to high data requirements, our results for agency costs and information asymmetry need to be interpreted with caution as the sample size reduces to values between 590 and 491 .

\section{Conclusion}

Prior research often truncated or removed negative premiums, regarding them as noise. We develop and test three theoretical explanations for negative premiums: 1) hidden earnouts, 2) overvaluation, and 3) market liquidity.

\section{A. Hidden Earnouts}


Any bid with an equity portion, where the bidder benefits from the acquisition, implies that target shareholders participate in the bidder's share of joint synergies through their ownership of the merged entity. These earnouts cannot be announced in the initial bid. They are hidden and must exist, as shown in Lemma 1. Proposition 1 proves that hidden earnouts explain negative premiums if synergies are sufficient. Negative offer premiums together with positive hidden earnouts result in a positive post-merger premium, fulfilling the target shareholders' participation constraint. To stay in control, bidders need to offer negative premiums together with hidden earnouts if the target is large (see Proposition 2). Our empirical results provide clear support for hidden earnouts as one explanation for negative premiums. Table IV demonstrates that bids with high equity portions and relative size trigger negative premiums. Our direct measure of hidden earnouts, based on Lemma 1, has explanatory power. Decomposing valuation levels based on Rhodes-Kropf et al. (2005) reveals that targets and bidders with high long run growth expectations and, as such, more synergy potential for hidden earnouts, exhibit negative premiums. The market should respond positively to the announcement of negative offer premiums with hidden earnouts (see Proposition 3). Sequential logistic regressions confirm this assertion (see Table VI). High-Q bidders signaling high joint synergies explain a positive market reaction to negative offer premiums. Our direct measure of hidden earnouts and large targets in combination with high equity portions also make a positive market response more likely.

\section{B. Overvaluation}

Proposition 4 focuses on the fundamental overvaluation of a target's stand-alone value. Logistic models confirm that targets with high Tobin's Q explain negative premiums (see 
Table IV). Proposition 5 states that excessive run-ups, capturing overstated expected gains from mergers, can also cause negative premiums. Table V indicates that the likelihood of negative premiums increases in run-ups. Using interaction terms between run-ups and the target's Tobin's Q, as well as the market volume of M\&As in the industry, underscores the fact that run-ups represent a separate explanation. Sequential logistic models confirm that the market reacts negatively to the announcement of negative premiums for overvalued targets. Targets with high firm and sector-specific overvaluation exhibit a market response in line with Proposition 6.

\section{Market Liquidity}

Proposition 7 explores the role of liquidity in the market for corporate control. We find only statistically weak support for the relevance of transaction volumes for negative premiums (Table IV). Related factors pertaining to fire sales lack explanatory power. The results also provide only limited support that financially constrained targets are prone to negative premiums and no support that illiquid target stock plays a role (Table W3). One could argue that marketability discounts due to block holding could partly explain negative premiums. Pratt (2009) contends that marketability discounts are in the region of $13.0 \%$ to $45.0 \%$. Reported discounts must be interpreted with caution, due to data availability, small samples, and often hand-collected data (Dlugosz, Fahlenbrach, Gompers, and Metrick, 2006). Our study uses bid-ask spreads and zero returns as proxies as ownership data is not available for a sufficient number of targets. These proxies do not explain the negative premiums.

Our findings go beyond negative premiums and hold for low positive premiums. In extensions, we find that our theory and empirical results can be generalized to the bottom $25 \%$ 
of all premiums, which include positive takeover premiums that reach a magnitude of $18.5 \%$. In fact, some determinants (e.g., firm and sector-specific overvaluation) are more powerful predictors for low premiums than for negative premiums alone. Managerial implications of our results include the direct estimation of hidden earnouts, derived from our model, which can be used to negotiate lower offer prices. In conclusion, the paper provides theoretical and empirical evidence that negative premiums do exist and are a rational phenomenon. Negative premiums should not be ignored; they should be studied. 


\section{References}

Altman, E.J., R. Haldeman, and P. Narayanan, 1977, “A New Model to Identify Bankruptcy Risk of Corporations," Journal of Banking \& Finance 1, 29-54.

Amemiya, T., 1985, Advanced Econometrics, Cambridge, MA, Harvard University Press.

Ang, J.S. and A.K. Ismail, 2015, “What Premiums Do Target Shareholders Expect?” Journal of Corporate Finance 30, 245-256.

Bargeron, L.L., F.P. Schlingemann, R.M. Stulz, and C.J. Zutter, 2009, “Do Target CEOs Sell Out Their Shareholders to Keep Their Job in a Merger?” Tech. Rep., National Bureau of Economic Research.

Barnes, B.G., N.L. Harp, and D. Oler, 2014, "Evaluating the SDC Mergers and Acquisitions Database," Financial Review 49, 793-822.

Bates, T.W. and M.L. Lemmon, 2003, “Breaking Up is Hard to Do? An Analysis of Termination Fee Provisions and Merger Outcomes," Journal of Financial Economics 69, 469504.

Betton, S., B.E. Eckbo, R. Thompson, and K.S. Thorburn, 2014, "Merger Negotiations with Stock Market Feedback," Journal of Finance 69, 1705-1745. 
Betton, S., B. Eckbo, and K. Thorburn, 2008, “Corporate Takeovers,” in B.E. Eckbo, Ed., Handbook of Corporate Finance: Empirical Corporate Finance, Vol. 2 of the Handbook of Finance Series, Amsterdam, Elsevier/North-Holland, 291-430.

Betton, S., B.E. Eckbo, and K.S. Thorburn, 2009, "Merger Negotiations and the Toehold Puzzle," Journal of Financial Economics 91, 158-178.

Bollaert, H. and M. Delanghe, 2015, "Securities Data Company and Zephyr, Data Sources for M\&A Research,” Journal of Corporate Finance 33, 85-100.

Boone, A.L. and J.H. Mulherin, 2007, “How Are Firms Sold?” Journal of Finance 62, 847875.

Clayton, M.J. and S.A. Ravid, 2002, “The Effect of Leverage on Bidding Behavior: Theory and Evidence from the FCC Auctions," Review of Financial Studies 15, 723-750.

Dechow, P., R. Sloan, and A. Sweeney, 1995, “Detecting Earnings Management,” The Accounting Review 70, 193-225.

Dlugosz, J., R. Fahlenbrach, P. Gompers, and A. Metrick, 2006, “Large Blocks of Stock: Prevalence, Size, and Measurement," Journal of Corporate Finance 12, 594-618. 
D’Mello, R. and P. Shroff, 2000, “Equity Undervaluation and Decisions Related to

Repurchase Tender Offers: An Empirical Investigation,” Journal of Finance 55, 2399-2424.

Dong, M., D. Hirshleifer, S. Richardson, and S.H. Teoh, 2006, "Does Investor Misevaluation Drive the Takeover Market?” Journal of Finance 61, 725-762.

Eckbo, B.E., 2009, “Bidding Strategies and Takeover Premiums: A Review,” Journal of Corporate Finance 15, 149-178.

Eckbo, E.B. and S.K. Thorburn, 2008, “Automatic Bankruptcy Auctions and Fire-Sales," Journal of Financial Economics 89, 404-422.

Fama, E. and K. French, 1997, “Industry Costs of Equity,” Journal of Financial Economics 43, 153-193.

Fishman, M.J., 1988, “A Theory of Preemptive Takeover Bidding,” RAND Journal of Economics 19, 88-101.

Gleason, K.C., L. Rosenthal, and R.A.I. Wiggins, 2005, “Backing into Being Public: An Exploratory Analysis of Reverse Takeovers," Journal of Corporate Finance 12, 54-79.

Greenwood, R. and M. Schor, 2009, "Hedge Fund Investor Activism and Takeovers,” Journal of Financial Economics 92, 362-375. 
Hartzell, J., E. Ofek, and D. Yermack, 2004, “What's In It for Me? Personal Benefits Obtained by CEOs Whose Firms are Acquired," Review of Financial Studies 17, 37-61.

Helwege, J., C. Pirinsky, and R.M. Stulz, 2007, "Why Do Firms Become Widely Held? An Analysis of the Dynamics of Corporate Ownership," Journal of Finance 62, 995-1028.

Hirshleifer, D., K. Hou, S. Teoh, and Y. Zhang, 2004, “Do Investors Overvalue Firms with Bloated Balance Sheets?" Journal of Accounting and Economics 38, 297-331.

Jarrell, G.A. and A.B. Poulsen, 1989, "Stock Trading Before the Announcement of Tender Offers: Insider Trading or Market Anticipation?" Journal of Law, Economics, \& Organization $5,225-248$.

Jensen, M.C., 1986, “Agency Costs of Free Cash Flow, Corporate Finance, and Takeovers," American Economic Review 76, 323-329.

Jovanovic, B. and P.L. Rousseau, 2002, “The Q-theory of Mergers," American Economic Review 92, 198-204.

Krishnan, H.A., M.A. Hitt, and D. Park, 2007, “Acquisition Premiums, Subsequent Workforce Reductions and Post-acquisition Performance," Journal of Management Studies 44, 709-732. 
Lang, H.L. and R.M. Stulz, 1992, “Contagion and Competitive Intra-industry Effects of Bankruptcy Announcements: An Empirical Analysis," Journal of Financial Economics 32, 45-60.

Lesmond, D., J. Ogden, and C. Trzcinka, 1999, “A New Estimate of Transaction Costs,” Review of Financial Studies 12, 1113-1141.

Liao, T.F., 1994, Interpreting Probability Models: Logit, Probit, and Other Generalized Linear Models, Thousand Oaks, CA, Sage.

Luypaert, M. and T. Van Caneghem, 2017, "Exploring the Double-Sided Effect of Information Asymmetry and Uncertainty in Mergers and Acquisitions," Financial Management, forthcoming.

Masulis, R.W., C. Wang, and F. Xie, 2007, "Corporate Governance and Acquirer Returns," Journal of Finance 62, 1851-1889.

Moeller, T., 2005, “Let’s Make a Deal! How Shareholder Control Impacts Merger Payoffs,” Journal of Financial Economics 76, 167-190.

Moeller, S.B., F.P. Schlingemann, and R.M. Stulz, 2004, "Firm Size and the Gains from Acquisitions," Journal of Financial Economics 73, 201-228. 
Mulherin, H. and S.A. Simsir, 2015, "Measuring Deal Premiums in Takeovers," Financial Management 44, 1-14.

Officer, M.S., 2003, “Termination Fees in Mergers and Acquisitions," Journal of Financial Economics 69, 431-467.

Officer, M.S., 2004, "Collars and Renegotiation in Mergers and Acquisitions," Journal of Finance 59, 2719-2743.

Officer, M.S., 2006, "The Market Pricing of Implicit Options in Merger Collars," Journal of Business 79, 115-136.

Officer, M.S., 2007, “The Price of Corporate Liquidity: Acquisition Discounts for Unlisted Targets," Journal of Financial Economics 83, 571-598.

Ohlson, J., 1995, "Earnings, Book Values, and Dividends in Equity Valuation," Contemporary Accounting Research 11, 661-687.

Pratt, S., 2009, Business Valuation Discounts and Premiums, 2nd Edition, Hoboken, NJ, John Wiley \& Sons.

Pulvino, T.C., 1998, "Do Asset Fire Sales Exist? An Empirical Investigation of Commercial Aircraft Transactions," Journal of Finance 53, 939-978. 
Ramey, V. and M. Shapiro, 2001, "Displaced Capital: A Study of Aerospace Plant Closings," Journal of Political Economy 109, 958-992.

Rhodes-Kropf, M., D. Robinson, and S. Viswanathan, 2005, "Valuation Waves and Merger Activity: The Empirical Evidence,” Journal of Financial Economics 77, 561-603.

Roll, R., 1984, “A Simple Implicit Measure of the Effective Bid Ask Spread in an Efficient Market," Journal of Finance 39, 1127-1139.

Sawicki, J. and K. Shrestha, 2008, "Insider Trading and Earnings Management,” Journal of Business Finance \& Accounting 35, 331-346.

Sawicki, J. and K. Shrestha, 2012, “Overvalued Equity and the Accruals Anomaly: Evidence from Insider Trades," Procedia Economics and Finance 2, 91-100.

Schlingemann, F.P., 2004, "Financing Decisions and Bidder Gains," Journal of Corporate Finance 10, 683-701.

Schlingemann, F.P., R.M. Stulz, and R. Walkling, 2002, "Divestitures and the Liquidity of the Market for Corporate Assets," Journal of Financial Economics 64, 117-144. 
Schwert, G.W., 1996, “Markup Pricing in Mergers and Acquisitions," Journal of Financial Economics 41, 153-162.

Shleifer, A. and R.W. Vishny, 1992, "Liquidation Values and Debt Capacity: A Market Equilibrium Approach," Journal of Finance 47, 1343-1366.

Sloan, R., 1996, "Do Stock Prices Fully Reflect Information in Accruals and Cash Flows about Future Earnings?” The Accounting Review 71, 289-315.

Thorburn, K.S., 2000, "Bankruptcy Auctions: Costs, Debt Recovery, and Firm Survival," Journal of Financial Economics 58, 337-368.

Todd, C.P., 1999, “Effects of Bankruptcy Court Protection on Asset Sales," Journal of Financial Economics 52, 151-186.

Viral, V.A., T.B. Sreedhar, and S. Anand, 2007, “Does Industry-wide Distress Affect Defaulted Firms? Evidence from Creditor Recoveries," Journal of Financial Economics 85, 787-821.

White, H., 1980, “A Heteroskedasticity-Consistent Covariance Matrix Estimator and a Direct Test for Heteroskedasticity,” Econometrica 48(4), 817-838. 
Whited, T.M. and G. Wu, 2006, "Financial Constraints Risk," Review of Financial Studies 19, $531-559$. 
Figure I. CARs and Daily Premiums (Current Target Stock Price/Announced Bid-1) for a Sample with Negative PREMIUM $(t=-20)$ and Negative Post-Announcement Premiums (PAP, $t=5)$.

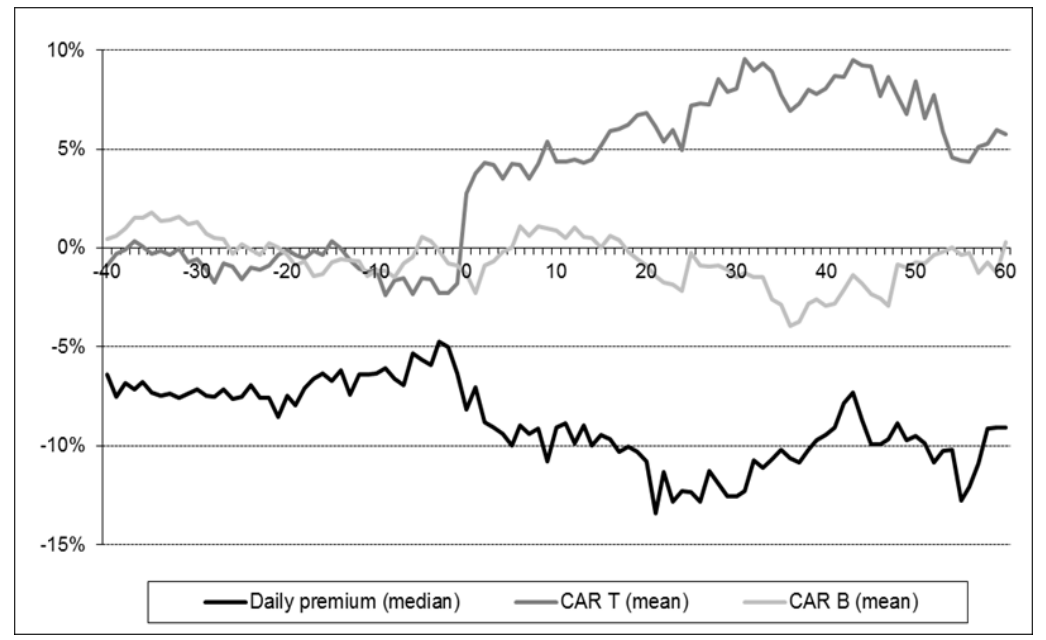


Figure II. CARs and Daily Premiums (Current Target Stock Price/Announced Bid-1) for a Sample with Negative PREMIUM $(t=-20)$ and Positive Post-Announcement Premiums (PAP, $t=5)$.

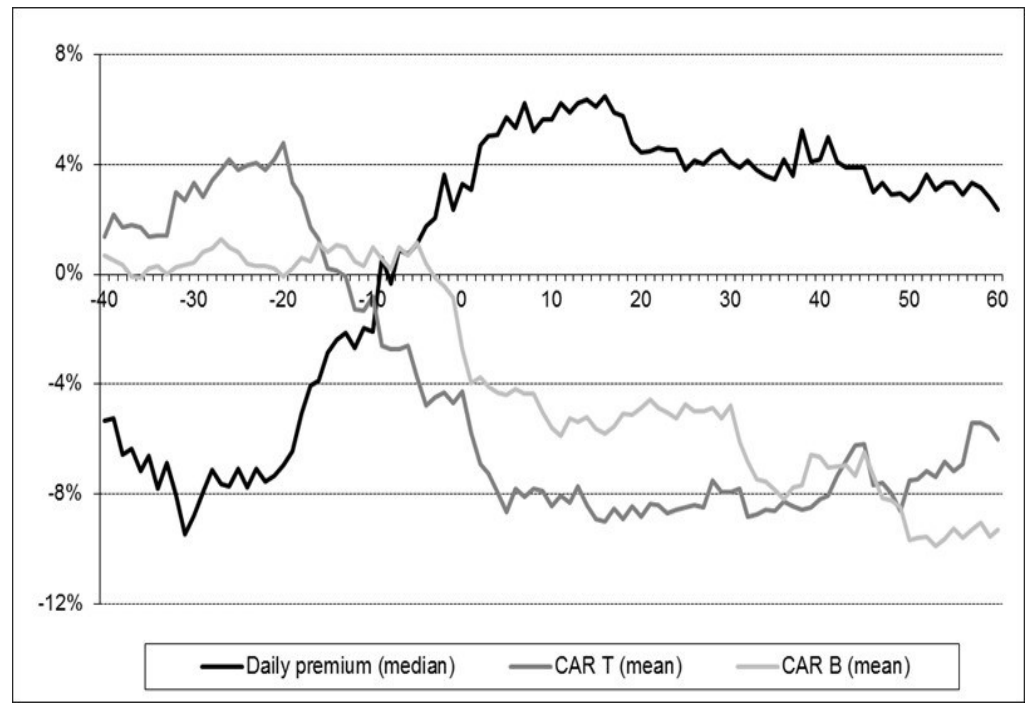


Table I. Variables and Definitions

\begin{tabular}{|c|c|}
\hline Variables & Definition \\
\hline & Prior to announcement: \\
\hline$K^{T}, K^{B}$ & Target's (bidder's) share price \\
\hline$N^{T}, N^{B}$ & Target's (bidder's) number of shares outstanding \\
\hline$v^{T}, v^{B}$ & Target's (bidder's) market value of equity \\
\hline$v_{f}^{T}, v_{f}^{B}$ & Target's (bidder's) fundamental value of equity \\
\hline$\delta T$ & Target's mispricing defined as $\mathrm{v}^{\mathrm{T}}-\mathrm{vf}^{\mathrm{T}}$ \\
\hline \multirow[t]{2}{*}{$v l^{T}$} & Target's (expected) liquidity value \\
\hline & At announcement: \\
\hline$b$ & Value of bid \\
\hline$p$ & Offer premium $\mathrm{p} \in[-1, \infty]$ \\
\hline$e$ & Equity portion of bid, e $\in[0,1]$ \\
\hline$X$ & Number of bidder shares exchanged for each target share \\
\hline$\lambda$ & Target's share of synergies announced in bid, $\lambda \in[0,1]$ \\
\hline \multirow[t]{2}{*}{$l$} & Liquidity discount of bid \\
\hline & After consummation: \\
\hline$b_{m}$ & Post-merger value of bid \\
\hline$p_{m}$ & Post-merger premium, $\mathrm{p}_{\mathrm{m}} \in[0, \infty]$ \\
\hline$\xi$ & Target's fraction of equity ownership in merged entity \\
\hline$K^{M}$ & Share price of merged entity \\
\hline$s$ & Synergies of merged entity \\
\hline
\end{tabular}




\section{Table II. Existence of Negative Premiums}

$\mathrm{N}$ (all) is the number of all non-missing offer premiums in our sample with a base price at $t=-20$. PREM is the average offer premium, while NEG indicates the number of negative premiums and their average value. PAP pos (neg) refers to the number of non-negative (negative) post-announcement premiums with a base price at $t=5$ after a negative offer premium. Four deals have missing base prices at $t=5$ resulting in $85+73=158$ post-announcement premiums. CAR pos (neg) refers to the number of non-negative (negative) cumulative abnormal returns to the target from $t=-1$ to $t=1$ given the offer premium is negative. The sum of CAR pos (CAR neg) is equal to the number of NEG (reported as \% of $\mathrm{N}$ ). Total refers to the number of observations $(\mathrm{N}, \mathrm{PAP}, \mathrm{CAR})$, averages (avg $\%, \%$ of $\mathrm{N})$, and 25 th percentiles $(\mathrm{p} 25)$.

\begin{tabular}{|c|c|c|c|c|c|c|c|}
\hline & $\begin{array}{r}\mathbf{N} \\
\text { (all) }\end{array}$ & $\begin{array}{c}\text { PREM } \\
\text { (avg \%) }\end{array}$ & $\begin{array}{l}\text { PREM } \\
\text { (p25) }\end{array}$ & $\begin{array}{c}\text { NEG } \\
(\% \text { of } N)\end{array}$ & $\begin{array}{c}\text { NEG } \\
(\operatorname{avg} \%)\end{array}$ & $\begin{array}{c}\text { PAP } \\
\text { pos (neg) }\end{array}$ & $\begin{array}{c}\text { CAR } \\
\text { pos (neg) }\end{array}$ \\
\hline 1995 & 115 & 40.55 & 22.44 & 6.96 & -17.23 & $2(6)$ & $2(6)$ \\
\hline 1996 & 143 & 36.64 & 14.58 & 10.49 & -9.27 & $10(5)$ & $7(8)$ \\
\hline 1997 & 191 & 35.49 & 14.36 & 11.52 & -13.61 & $10(12)$ & $7(15)$ \\
\hline 1998 & 217 & 48.58 & 19.26 & 9.68 & -10.79 & $14(7)$ & $9(12)$ \\
\hline 1999 & 224 & 55.95 & 28.32 & 6.25 & -14.58 & $8(5)$ & $7(7)$ \\
\hline 2000 & 209 & 50.25 & 19.39 & 10.05 & -17.25 & $12(8)$ & $14(7)$ \\
\hline 2001 & 131 & 46.81 & 14.01 & 12.98 & -20.90 & $8(8)$ & $10(7)$ \\
\hline 2002 & 64 & 42.80 & 15.59 & 14.06 & -19.82 & $7(1)$ & $4(5)$ \\
\hline 2003 & 81 & 42.89 & 18.86 & 6.17 & -19.42 & $1(4)$ & $3(2)$ \\
\hline 2004 & 78 & 30.89 & 9.15 & 14.10 & -17.31 & $5(6)$ & $5(6)$ \\
\hline 2005 & 83 & 31.08 & 16.34 & 6.02 & -10.08 & $2(3)$ & $1(4)$ \\
\hline 2006 & 86 & 35.30 & 19.97 & 2.33 & -5.08 & $1(1)$ & $2(0)$ \\
\hline 2007 & 98 & 32.68 & 15.70 & 4.08 & -15.39 & $2(2)$ & $2(2)$ \\
\hline 2008 & 73 & 44.18 & 23.06 & 5.48 & -27.55 & $2(2)$ & $2(2)$ \\
\hline 2009 & 55 & 48.78 & 18.94 & 1.82 & -23.01 & $1(0)$ & $0(1)$ \\
\hline 2010 & 66 & 51.56 & 24.48 & 3.03 & -22.16 & $0(2)$ & $1(1)$ \\
\hline 2011 & 23 & 26.69 & 16.96 & 4.35 & -17.47 & $0(1)$ & $1(0)$ \\
\hline Total & 1937 & 43.24 & 18.49 & 8.36 & -15.48 & $85(73)$ & $77(85)$ \\
\hline
\end{tabular}




\section{Table III. Descriptive Statistics}

$\mathrm{T}$ (B) refers to the target (bidder). PREMIUM is the offer premium with a base price at $t=-20$. RUNUP is the market adjusted buy and hold return to the target from $t=-20$ to $t=-1$. TQ is Tobin's Q. CAR is the market-adjusted cumulative abnormal return from $t=-1$ to $t=1$. FIRM, SECTOR, and LONG are the decomposed valuation levels. HE is the direct measure of hidden earnouts. EQ is the percentage of equity offered. NEW EQ50 indicates whether bidders issue more than $50 \%$ of equity. RSIZE is the ratio of the target over bidder market value at $t=-20$. BIG T indicates whether the target is larger than the bidder. MKT BIDS and MKT VOL is the monthly frequency and deal volume of all domestic M\&As in the two-digit SIC target industry. LEVERAGE is total debt to equity, SHORT DEBT is short over long-term debt, CASH TA is cash and cash equivalents over total assets, and WC TA is working capital over total assets. ROIC is earnings before interest and taxes over fixed assets, TURNOVER is revenues over fixed assets, and CI is operating costs over revenues. NUMBID is a dummy for more than one bidder. TENDER is a dummy for tender offers. HORIZONTAL is a dummy for mergers in the same four-digit SIC industry. WITHDRAWN is a dummy for withdrawn offers. HOSTILE is a dummy for mergers that SDC classifies as hostile.

\begin{tabular}{|c|c|c|c|c|c|c|c|c|}
\hline & $\mathbf{N}$ & mean & sd & $\min$ & p25 & p50 & p75 & $\max$ \\
\hline PREMIUM & 1,937 & 43.24 & 41.08 & -45.53 & 18.50 & 35.76 & 60.78 & 213.34 \\
\hline RUNUP & 1,935 & 0.09 & 0.20 & -0.38 & -0.03 & 0.05 & 0.17 & 0.85 \\
\hline TQ T & 1,927 & 2.45 & 2.61 & 0.54 & 1.21 & 1.63 & 2.52 & 18.46 \\
\hline TQ B & 1,781 & 3.22 & 3.81 & 0.74 & 1.45 & 2.06 & 3.19 & 27.05 \\
\hline CAR T & 1,910 & 0.22 & 0.25 & -0.26 & 0.05 & 0.18 & 0.33 & 1.25 \\
\hline CAR B & 1,892 & -0.02 & 0.08 & -0.28 & -0.06 & -0.01 & 0.02 & 0.26 \\
\hline FIRM T & 1,841 & -0.88 & 1.25 & -7.16 & -1.64 & -0.91 & -0.19 & 5.83 \\
\hline FIRM B & 1,745 & -0.45 & 1.30 & -6.80 & -1.14 & -0.48 & 0.24 & 7.54 \\
\hline SECTOR T & 1,841 & -0.04 & 1.02 & -8.65 & -0.38 & -0.06 & 0.43 & 3.59 \\
\hline SECTOR B & 1,775 & -0.04 & 0.97 & -8.66 & -0.27 & -0.04 & 0.37 & 2.76 \\
\hline LONG T & 1,841 & 1.83 & 0.64 & 0.93 & 1.53 & 1.80 & 1.93 & 5.33 \\
\hline LONG B & 1,775 & 1.74 & 0.63 & 0.88 & 1.41 & 1.68 & 1.83 & 5.25 \\
\hline $\mathrm{HE}$ & 1,848 & -0.08 & 0.14 & -0.76 & -0.09 & -0.01 & 0.00 & 0.09 \\
\hline EQ & 1,937 & 54.58 & 46.96 & 0.00 & 0.00 & 75.16 & 100.00 & 100.00 \\
\hline NEW EQ50 & 1,937 & 0.03 & 0.16 & 0.00 & 0.00 & 0.00 & 0.00 & 1.00 \\
\hline RSIZE & 1,879 & 0.31 & 0.46 & 0.00 & 0.04 & 0.14 & 0.39 & 2.99 \\
\hline BIG T & 1,937 & 0.18 & 0.39 & 0.00 & 0.00 & 0.00 & 0.00 & 1.00 \\
\hline MKT BIDS & 1,922 & 32.12 & 37.83 & 1.00 & 8.00 & 15.00 & 32.00 & 156.00 \\
\hline MKT VOL & 1,922 & 3.72 & 7.15 & 0.00 & 0.44 & 1.32 & 3.55 & 44.34 \\
\hline LEVERAGE & 1,523 & 0.55 & 1.17 & -1.71 & 0.06 & 0.25 & 0.61 & 8.66 \\
\hline SHORT DEBT & 1,343 & 0.36 & 0.35 & 0.00 & 0.05 & 0.23 & 0.64 & 1.00 \\
\hline CASH TA & 1,905 & 0.22 & 0.24 & 0.00 & 0.03 & 0.13 & 0.37 & 0.88 \\
\hline
\end{tabular}




\section{Table IV. Determinants of Negative Premiums Using Logistic Regressions}

(A) is the reference model. (B) and (C) decompose valuation levels. (D) includes the direct measure of hidden earnouts and accounts for large targets. (E) focuses on targets' profitability, while (F) on targets' financial health. We account for industry-specific effects with dummies for targets' and bidders' SIC codes and include year dummies. Standard errors refer to the Huber-White (1980) estimator. ${ }^{*} \mathrm{p}<0.05,{ }^{* *} \mathrm{p}<0.01$, and ${ }^{* * *} \mathrm{p}<0.001$.

\begin{tabular}{|c|c|c|c|c|c|c|}
\hline & (A) & (B) & (C) & (D) & (E) & $(F)$ \\
\hline TQ T & $0.144 * * *$ & & & $0.156^{* * *}$ & $0.124^{*}$ & $0.097^{* *}$ \\
\hline TQ B & $-0.094 *$ & & & $-0.116^{*}$ & $-0.142 *$ & -0.060 \\
\hline FIRM T & & 0.061 & & & & \\
\hline SECTOR T & & 0.185 & & & & \\
\hline LONG T & & $0.480^{*}$ & & & & \\
\hline FIRM B & & & -0.019 & & & \\
\hline SECTOR B & & & 0.139 & & & \\
\hline LONG B & & & $0.566^{* *}$ & & & \\
\hline EQ & $0.010^{* * *}$ & $0.014 * * *$ & $0.012 * * *$ & $0.018^{* * *}$ & $0.019 * * *$ & $0.011 *$ \\
\hline NEW EQ50 & 0.597 & 0.160 & 0.227 & $1.346^{*}$ & 1.162 & 0.087 \\
\hline RSIZE & $0.772 * * *$ & $1.030 * * *$ & $0.779 * * *$ & $0.736^{* *}$ & 0.600 & $0.822 * *$ \\
\hline BIG T & & & & 0.485 & 0.339 & \\
\hline $\mathrm{HE}$ & & & & $19.968 * * *$ & $26.404 * * *$ & \\
\hline ROIC & & & & & -0.003 & \\
\hline TURNOVER & & & & & 0.177 & \\
\hline $\mathrm{CI}$ & & & & & 0.116 & \\
\hline MKT BIDS & -0.004 & -0.007 & -0.007 & 0.003 & 0.004 & 0.000 \\
\hline MKT VOL & $-0.070^{*}$ & $-0.045^{*}$ & $-0.039^{*}$ & $-0.063^{* *}$ & $-0.072 *$ & $-0.140 * * *$ \\
\hline LEVERAGE & & & & & & $-0.373^{*}$ \\
\hline SHORT DEBT & & & & & & 0.238 \\
\hline CASH TA & & & & & & 1.521 \\
\hline WC TA & & & & & & $-1.416^{*}$ \\
\hline LIAB & & & & & & 0.175 \\
\hline NUMBID & 0.511 & 0.175 & 0.232 & 0.024 & -0.003 & 0.692 \\
\hline TENDER & -0.426 & -0.370 & -0.441 & -0.399 & -0.455 & -0.396 \\
\hline HORIZONTAL & 0.135 & 0.286 & 0.114 & 0.222 & 0.439 & 0.216 \\
\hline WITHDRAWN & 0.230 & 0.309 & 0.329 & 0.257 & 0.100 & 0.165 \\
\hline HOSTILE & -0.310 & -0.081 & -0.175 & 0.035 & 0.597 & -0.582 \\
\hline 11 & -416.472 & -401.685 & -399.491 & -327.13 & -188.767 & -224.587 \\
\hline aic & 910.944 & 889.369 & 866.981 & 744.26 & 427.534 & 543.175 \\
\hline bic & $1,124.548$ & $1,125.052$ & $1,052.599$ & 990.034 & 552.611 & 775.092 \\
\hline $\mathrm{r} 2 \mathrm{p}$ & 0.149 & 0.159 & 0.149 & 0.307 & 0.33 & 0.171 \\
\hline $\mathrm{N}$ & 1,767 & 1,774 & 1,736 & 1,740 & 1,100 & 1,027 \\
\hline
\end{tabular}




\section{Table V. Run-ups}

Logistic regressions with negative premiums as dependent. Premiums refer to $t=1$ so that measurement periods for run-ups $(t=$ 20 to $t=1$ ) and premiums do not overlap. (G) re-estimates our reference Model (A) (see Table IV). (H) includes run-ups. (I) and $(\mathrm{J})$ replace Tobin's $\mathrm{Q}$ with firm, sector, and long run overvaluation. $(\mathrm{K})$ considers the interaction term between run-ups and Tobin's Q (RUNUPxTQ T). (L) uses the interaction between run-ups and the M\&A transaction volume in the industry (RUNUPxVOL). We account for industry-specific effects with dummies for targets' and bidders' SIC codes and include year dummies. Standard errors refer to the Huber-White (1980) estimator. ${ }^{*} \mathrm{p}<0.05,{ }^{* *} \mathrm{p}<0.01$, and ${ }^{* * *} \mathrm{p}<0.001$.

\begin{tabular}{|c|c|c|c|c|c|c|}
\hline & (G) & (H) & (I) & (J) & (K) & (L) \\
\hline TQ T & $0.127 * * *$ & $0.125^{* * *}$ & & & $0.166^{* * *}$ & $0.128^{* * *}$ \\
\hline TQ B & -0.061 & -0.069 & & & -0.063 & -0.073 \\
\hline RUNUP & & $1.576^{* *}$ & $1.574 * *$ & $1.323 * *$ & $2.701 * * *$ & $1.156^{*}$ \\
\hline RUNUPxTQ T & & & & & $-0.322 * *$ & \\
\hline RUNUPxVOL & & & & & & $0.116^{*}$ \\
\hline FIRM T & & & -0.116 & & & \\
\hline SECTOR T & & & -0.028 & & & \\
\hline LONG T & & & 0.128 & & & \\
\hline FIRM B & & & & -0.240 & & \\
\hline SECTOR B & & & & -0.046 & & \\
\hline LONG B & & & & 0.391 & & \\
\hline EQ & $0.008 * *$ & $0.008 * *$ & $0.011^{* * *}$ & $0.010^{* *}$ & $0.008 * *$ & $0.008 * *$ \\
\hline NEW EQ50 & 0.338 & 0.325 & -0.037 & 0.322 & 0.321 & 0.328 \\
\hline RSIZE & $0.542 * *$ & $0.652 * * *$ & $0.926^{* * *}$ & $0.524 *$ & $0.669 * * *$ & $0.667 * * *$ \\
\hline MKT BIDS & 0.000 & -0.001 & -0.002 & -0.002 & -0.003 & -0.001 \\
\hline MKT VOL & -0.036 & -0.035 & -0.037 & -0.036 & -0.035 & $-0.066^{*}$ \\
\hline NUMBID & 0.527 & 0.489 & 0.442 & 0.330 & 0.504 & 0.513 \\
\hline TENDER & -0.432 & -0.475 & -0.580 & -0.327 & -0.521 & -0.452 \\
\hline HORIZONTAL & -0.036 & -0.019 & 0.013 & -0.093 & -0.005 & -0.007 \\
\hline WITHDRAWN & -0.298 & -0.267 & -0.524 & -0.110 & -0.290 & -0.293 \\
\hline HOSTILE & -0.929 & -0.778 & 0.000 & 0.000 & -0.712 & -0.783 \\
\hline 11 & -449.331 & -443.020 & -425.209 & -417.791 & -437.834 & -440.791 \\
\hline aic & 976.662 & 972.041 & 936.417 & 919.581 & 943.667 & 965.581 \\
\hline bic & $1,190.223$ & $1,207.505$ & $1,169.088$ & $1,145.865$ & $1,129.848$ & $1,195.569$ \\
\hline $\mathrm{r} 2 \mathrm{p}$ & 0.112 & 0.125 & 0.122 & 0.114 & 0.135 & 0.129 \\
\hline $\mathrm{N}$ & 1,765 & 1,765 & 1,654 & 1,616 & 1,765 & 1,765 \\
\hline
\end{tabular}




\section{Table VI. Market Response to Hidden Earnouts}

Second step sequential logistic models distinguish between negative premiums that remain negative, with a PAP base price at $t=$ 5, and those that become positive. (M) is our standard specification, and $(\mathrm{N})$ and $(\mathrm{O})$ use decomposed valuation levels. (P) and (Q) add the direct measure of hidden earnouts. (Q) includes abnormal returns. (R) adds run-ups. We account for industry-specific effects with dummies for targets' and bidders' SIC codes and include year dummies. Standard errors refer to the Huber-White (1980) estimator. ${ }^{*} \mathrm{p}<0.05,{ }^{* *} \mathrm{p}<0.01$, and ${ }^{* * *} \mathrm{p}<0.001$.

\begin{tabular}{|c|c|c|c|c|c|c|}
\hline & (M) & (N) & (0) & (P) & (Q) & (R) \\
\hline TQ T & $-0.162 *$ & & & -0.124 & -0.010 & -0.088 \\
\hline TQ B & $0.255^{*}$ & & & 0.166 & $0.256^{*}$ & $0.271^{*}$ \\
\hline FIRM T & & -0.181 & & & & \\
\hline SECTOR T & & 0.044 & & & & \\
\hline LONG T & & -0.209 & & & & \\
\hline FIRM B & & & -0.494 & & & \\
\hline SECTOR B & & & -0.672 & & & \\
\hline LONG B & & & 0.746 & & & \\
\hline $\mathrm{HE}$ & & & & $13.611^{*}$ & $19.504^{*}$ & \\
\hline RUNUP & & & & & & 2.325 \\
\hline CAR B & & & & & $9.100^{*}$ & \\
\hline CAR T & & & & & $5.766^{* *}$ & \\
\hline EQ & 0.005 & 0.023 & $0.023 *$ & -0.006 & -0.008 & -0.009 \\
\hline NEW EQ50 & -2.108 & -0.108 & 0.351 & & & \\
\hline RSIZE & 0.576 & -0.113 & -0.482 & -0.485 & -0.229 & 0.155 \\
\hline BIG T & 1.332 & 0.667 & 0.750 & $-8.127 *$ & $-10.877 * * *$ & $-6.740 * *$ \\
\hline EQxBIG T & & & & $0.100^{*}$ & $0.132 * * *$ & 0.089 \\
\hline MKT BIDS & & & & & 0.010 & 0.002 \\
\hline MKT VOL & & & & & -0.337 & $-0.480 * *$ \\
\hline NUMBID & -2.161 & -0.452 & 0.594 & -0.949 & 1.611 & -1.050 \\
\hline TENDER & 0.318 & 0.755 & 1.753 & -1.026 & -0.626 & -0.724 \\
\hline HORIZONTAL & $1.341 *$ & 0.182 & 0.934 & $1.834 * *$ & $1.754^{*}$ & $1.328^{*}$ \\
\hline WITHDRAWN & -0.600 & -0.772 & -0.378 & -0.468 & -1.098 & -1.028 \\
\hline HOSTILE & -0.470 & 2.158 & 1.946 & $4.521^{*}$ & $7.422 * *$ & $6.140^{*}$ \\
\hline 11 & -64.112 & -66.508 & -65.073 & -58.193 & -45.344 & -56.867 \\
\hline aic & 202.225 & 207.016 & 204.147 & 192.387 & 174.689 & 193.734 \\
\hline bic & 309.167 & 311.366 & 308.497 & 301.353 & 294.801 & 309.348 \\
\hline $\mathrm{r} 2 \mathrm{p}$ & 0.300 & 0.211 & 0.218 & 0.349 & 0.488 & 0.379 \\
\hline $\mathrm{N}$ & 133 & 124 & 124 & 130 & 129 & 133 \\
\hline
\end{tabular}




\section{Table VII. Market Response to Overvaluation}

The second step of sequential logistic models distinguishing between negative offer premiums with a negative abnormal return (one if CAR $T<0$ ) and a non-negative return (zero if CAR $T \geq 0$ ). Starting with the basic specification $(\mathrm{S})$, ( $\mathrm{T}$ ), and (U) replace Tobin's Q with decomposed valuation levels. (V) adds run-ups, the interaction effect between run-ups and the target's valuation in (W), the direct measure of hidden earnouts in (X), and the bidder's abnormal market response, as well as proxies for liquidity in (Y). We account for industry-specific effects with dummies for targets' and bidders' SIC codes and include year dummies. Standard errors refer to the Huber-White (1980) estimator. ${ }^{*} \mathrm{p}<0.05,{ }^{* *} \mathrm{p}<0.01$, and ${ }^{* * *} \mathrm{p}<0.001$.

\begin{tabular}{|c|c|c|c|c|c|c|c|}
\hline & (S) & (T) & (U) & (V) & (W) & (X) & (Y) \\
\hline TQ T & $0.207^{* *}$ & & & $0.190^{*}$ & $0.146^{*}$ & $0.176^{*}$ & 0.151 \\
\hline TQ B & -0.112 & & & -0.161 & -0.216 & $-0.292 *$ & $-0.337 *$ \\
\hline FIRM T & & $0.619^{*}$ & & & & & \\
\hline SECTOR T & & $0.929 *$ & & & & & \\
\hline LONG T & & -0.005 & & & & & \\
\hline FIRM B & & & 0.062 & & & & \\
\hline SECTOR B & & & 0.470 & & & & \\
\hline LONG B & & & -0.372 & & & & \\
\hline RUNUP & & & & $7.840 * * *$ & $11.209^{* * *}$ & $11.906^{* * *}$ & $14.480 * * *$ \\
\hline RUNUPxTQ T & & & & & $-1.090^{* *}$ & $-0.954 * *$ & $-1.271^{*}$ \\
\hline CAR B & & & & & & & $-8.084 *$ \\
\hline $\mathrm{HE}$ & & & & & & 1.924 & \\
\hline EQ & 0.002 & -0.003 & -0.005 & -0.003 & -0.004 & 0.000 & -0.002 \\
\hline NEW EQ50 & -0.317 & -0.340 & -1.286 & -0.347 & -0.307 & 0.330 & -0.504 \\
\hline RSIZE & 0.400 & 0.708 & 0.644 & 0.438 & 0.406 & 0.096 & 0.213 \\
\hline MKT BIDS & & & & & & & 0.024 \\
\hline MKT VOL & & & & & & & 0.007 \\
\hline NUMBID & $2.699 *$ & 2.248 & 1.766 & 2.124 & 2.538 & 2.677 & 3.060 \\
\hline TENDER & 1.601 & -0.814 & -0.273 & 0.514 & 0.721 & 0.830 & 1.053 \\
\hline HORIZONTAL & -0.684 & $-1.128 *$ & -0.056 & -0.713 & -0.780 & -0.827 & -0.986 \\
\hline WITHDRAWN & -0.588 & -0.127 & 0.194 & -0.351 & -0.101 & -0.025 & -0.017 \\
\hline 11 & -74.965 & -69.844 & -77.620 & -64.336 & -61.032 & -55.104 & -52.287 \\
\hline aic & 219.929 & 211.688 & 215.240 & 200.671 & 196.064 & 184.209 & 182.573 \\
\hline bic & 321.872 & 314.361 & 301.266 & 305.527 & 303.832 & 289.151 & 294.106 \\
\hline $\mathrm{r} 2 \mathrm{p}$ & 0.204 & 0.212 & 0.137 & 0.317 & 0.352 & 0.368 & 0.415 \\
\hline $\mathrm{N}$ & 136 & 128 & 130 & 136 & 136 & 126 & 129 \\
\hline
\end{tabular}




\section{Table VIII. Regional Samples and Determinants of Negative Premiums}

The WHOLE SAMPLE includes all merger announcements in SDC from 1995-2011, where public bidders seek to acquire full ownership of public targets and excludes regulated target industries (financials, SIC 6..., and utilities, SIC 49..) and deal values that are smaller than 10 mil \$. AM, EU, and AP denote target regions North America (USA, CAN), Europe, and Asia-Pacific (incl. Japan), respectively, as defined in SDC. NEG (\% of N) and NEG (median \%) report frequencies and medians for negative premiums. Self-dealing refers to self-tenders and repurchases and bids where both parties have the same ultimate parent. "Toehold YES" dummies bidders with target shares prior to the bid. "Mandatory YES" dummies mandatory offers. "Reverse YES" dummies reverse takeover bids. "Other YES" dummies bids that are not first bids, multiple bids on the same day by the same bidder, asset swaps, joint ventures, estimated and rumored announcement dates, and bankrupt or liquidated targets. The SUBSAMPLE refers to actual negative premiums after accounting for the reasons mentioned above. Note that SUBSAMPLE AM differs from the main sample in this paper as the former includes cross border deals and Canadian deals.

\begin{tabular}{|c|c|c|c|c|c|}
\hline Region & & All & AM & AP & EU \\
\hline \multicolumn{6}{|l|}{ WHOLE SAMPLE } \\
\hline $\mathrm{N}$ & & 6,592 & 3,912 & 1,310 & 1,370 \\
\hline $\mathrm{NEG}(\%$ of $\mathrm{N})$ & & 0.10 & 0.08 & 0.11 & 0.13 \\
\hline NEG (median \%) & & -11.04 & -10.58 & -12.35 & -10.47 \\
\hline NEG & $\%$ of $\mathbf{N}$ & median (\%) & $\%$ of $\mathbf{N}$ & $\%$ of $\mathbf{N}$ & $\%$ of $\mathrm{N}$ \\
\hline Self-dealing $\mathrm{NO}(\mathrm{N}=5,734)$ & 0.10 & -11.57 & 0.07 & 0.10 & 0.12 \\
\hline Self-dealing YES $(\mathrm{N}=858)$ & 0.16 & -9.71 & 0.10 & 0.19 & 0.16 \\
\hline Toehold NO $(\mathrm{N}=5,018)$ & 0.09 & -11.95 & 0.08 & 0.10 & 0.14 \\
\hline Toehold YES $(\mathrm{N}=1,574)$ & 0.15 & -9.85 & 0.09 & 0.14 & 0.12 \\
\hline Mandatory $\mathrm{NO}(\mathrm{N}=6,506)$ & 0.10 & -11.14 & 0.08 & 0.11 & 0.13 \\
\hline Mandatory YES $(\mathrm{N}=86)$ & 0.15 & -2.82 & & 0.22 & 0.07 \\
\hline Reverse NO $(\mathrm{N}=6,362)$ & 0.10 & -10.67 & 0.07 & 0.11 & 0.12 \\
\hline Reverse YES $(\mathrm{N}=230)$ & 0.22 & -14.47 & 0.16 & 0.23 & 0.30 \\
\hline Other $\mathrm{NO}(\mathrm{N}=5,142)$ & 0.10 & -9.71 & 0.07 & 0.11 & 0.12 \\
\hline Other YES $(\mathrm{N}=1,450)$ & 0.12 & -15.61 & 0.09 & 0.12 & 0.16 \\
\hline \multicolumn{6}{|l|}{ SUBSAMPLE } \\
\hline $\mathrm{N}$ & & 3,680 & 2,792 & 522 & 366 \\
\hline NEG $(\%$ of $N)$ & & 0.08 & 0.07 & 0.09 & 0.10 \\
\hline NEG (median \%) & & -10.11 & -9.60 & -11.57 & -9.93 \\
\hline NEG & $\%$ of $\mathbf{N}$ & median (\%) & $\%$ of $\mathrm{N}$ & $\%$ of $\mathrm{N}$ & $\%$ of $\mathrm{N}$ \\
\hline HORIZONTAL $0(\mathrm{~N}=2,166)$ & 0.07 & -11.14 & 0.06 & 0.08 & 0.08 \\
\hline HORIZONTAL $1(\mathrm{~N}=1,514)$ & 0.09 & -9.47 & 0.08 & 0.09 & 0.13 \\
\hline CROSS BORDER $0(\mathrm{~N}=2,773)$ & 0.09 & -9.76 & 0.07 & 0.11 & 0.11 \\
\hline CROSS BORDER $1(\mathrm{~N}=907)$ & 0.05 & -10.93 & 0.04 & 0.06 & 0.07 \\
\hline NUMBID $0(\mathrm{~N}=3,439)$ & 0.08 & -10.14 & 0.07 & 0.09 & 0.10 \\
\hline NUMBID $1(\mathrm{~N}=241)$ & 0.07 & -9.76 & 0.08 & 0.04 & 0.09 \\
\hline WITHDRAWN $0(\mathrm{~N}=3,149)$ & 0.07 & -9.71 & 0.06 & 0.08 & 0.09 \\
\hline WITHDRAWN $1(\mathrm{~N}=531)$ & 0.11 & -10.96 & 0.09 & 0.12 & 0.14 \\
\hline TENDER $0(\mathrm{~N}=2,395)$ & 0.10 & -9.76 & 0.08 & 0.17 & 0.15 \\
\hline TENDER $1(\mathrm{~N}=1,285)$ & 0.04 & -10.63 & 0.03 & 0.06 & 0.05 \\
\hline HOSTILE $0(\mathrm{~N}=3,552)$ & 0.08 & -10.11 & 0.07 & 0.09 & 0.10 \\
\hline HOSTILE $1(\mathrm{~N}=128)$ & 0.05 & -7.70 & 0.06 & 0.00 & 0.06 \\
\hline
\end{tabular}




\begin{tabular}{llllll} 
STOCK 0 $(\mathrm{N}=2,296)$ & 0.05 & -9.35 & 0.05 & 0.05 & 0.08 \\
STOCK 1 $(\mathrm{N}=1,384)$ & 0.13 & -10.48 & 0.11 & 0.16 & 0.13 \\
CASH 0 $(\mathrm{N}=2,451)$ & 0.10 & -10.16 & 0.09 & 0.13 & 0.12 \\
CASH 1 $(\mathrm{N}=1,229)$ & 0.03 & -6.99 & 0.02 & 0.02 & 0.05 \\
\hline
\end{tabular}




\section{Web Appendix A (Proofs)}

\section{Proof of Lemma 1}

Using results in the proof of Proposition 1 and the definition of hidden earnouts $\pi_{\mathrm{h}}=\mathrm{p}_{\mathrm{m}}-\mathrm{p}$, we obtain the following:

$\pi_{h}=p_{m}-p$

$\pi_{h} v_{f}^{T}=e b \frac{K^{M}}{K^{B}}+(1-e) b-b$

$\pi_{h} v_{f}^{T}=e b\left(\frac{K^{M}}{K^{B}}-1\right)$

$\pi_{h}=\frac{e b}{v_{f}^{T}}\left(\frac{v_{f}^{B}+v_{f}^{T}+s-(1-e) b-v_{f}^{B}-e b}{v_{f}^{B}+e b}\right)$

$\pi_{h}=\frac{e b}{v_{f}^{T}}\left(\frac{v_{f}^{T}+s-b}{v_{f}^{B}+e b}\right)$

Thus, $\pi_{\mathrm{h}}=0$ if $\mathrm{e}=0$ or $\mathrm{b}=\mathrm{v}_{\mathrm{f}}^{\mathrm{T}}+\mathrm{s}$ so that only the target gains from the acquisition by getting all of the synergies (i.e., $\lambda=1$ ).

\section{Proof of Proposition 1}

Using definition (5) and the post-merger value of the bid (4), the participation constraint demands the following inequality.

$p_{m}=\frac{X N^{T} K^{M}+(1-e) b}{v_{f}^{T}}-1>0$

Inserting the stock exchange rate $\mathrm{X}=\mathrm{eb} /\left(\mathrm{K}^{\mathrm{B}} \mathrm{N}^{\mathrm{T}}\right)$ based on $(2)$ and $\mathrm{K}^{\mathrm{M}}(3)$ under the assumption $e$ $>0$, the inequality becomes:

$$
\begin{aligned}
& e b \frac{K^{M}}{K^{B}}+(1-e) b>v_{f}^{T} \\
& e b \frac{v_{f}^{B}+v_{f}^{T}+s-(1-e) b}{v_{f}^{B}+e b}+(1-e) b>v_{f}^{T}
\end{aligned}
$$


$v_{f}^{B}+v_{f}^{T}+s-(1-e) b+(1-e) b+\frac{1-e}{e} v_{f}^{B}>\frac{v_{f}^{T}}{e b}\left(v_{f}^{B}+e b\right)$

$v_{f}^{T}+s+\frac{v_{f}^{B}}{e}>\frac{v_{f}^{T} v_{f}^{B}}{e b}+v_{f}^{T}$

$s>\frac{v_{f}^{B}}{e}\left(\frac{v_{f}^{T}}{b}-1\right)$

Then. from (1) and without mispricing, $\mathrm{b} / \mathrm{v}_{\mathrm{f}}^{\mathrm{T}}=\mathrm{p}+1$ gives the following:

$\frac{s}{v_{f}^{B}}>\frac{1}{e}\left(\frac{-p}{1+p}\right)$

\section{Proof of Proposition 2}

By definition $\xi=\frac{X N^{T}}{N^{B}+X N^{T}}=\frac{e b}{v_{f}^{B}+e b}$; thus, $\xi<0.5$ defines an upper bound for $b$.

$e b<0.5 v_{f}^{B}+0.5 e b \leftrightarrow b<\frac{v_{f}^{B}}{e}$

Thus, as $\mathrm{vf}_{\mathrm{f}}^{\mathrm{T}}>\mathrm{b} \rightarrow \mathrm{p}<0$ (1), the upper bound of $\mathrm{b}$ is violated for $\mathrm{vf}_{\mathrm{f}}^{\mathrm{T}}>\mathrm{vf}_{\mathrm{f}}^{\mathrm{B}} / \mathrm{e}$, resulting in a negative premium.

\section{Proof of Proposition 4}

From the participation constraint $\left(\mathrm{p}_{\mathrm{m}}>0\right)$, assumption $\mathrm{A}-4$, and the results in the proof of Proposition 1, we obtain the following inequality:

$s>\frac{v_{f}^{B}}{e}\left(\frac{v_{f}^{T}}{b}-1\right) \leftrightarrow \frac{e s}{v_{f}^{B}}+1>\frac{v_{f}^{T}}{b}$

$\frac{e s+v_{f}^{B}}{v_{f}^{B} v_{f}^{T}}>\frac{1}{b} \leftrightarrow b>\frac{v_{f}^{B} v_{f}^{T}}{e s+v_{f}^{B}}$ 
Using Assumption A-3, a fair bid reflects the target's fundamental value and the negotiated share of synergies $b=\lambda s+v_{f}^{T}$, which completes the proof. 


\section{Table W1. Robustness to Different Premium Measures}

Reference Model (A) with six alternative premium measures. (R1) refers to our standard base price at $t=-20$, but excludes slightly negative premiums, which may be due to noise, by coding negative premiums (that are) smaller than $-5 \%$ with a dummy equal to one. (R2) refers to our standard base price at $t=-20$, but without adjusting for changes in the S\&P 500 Index. (R3) and (R4) compute index-adjusted premiums with a base price at $t=-5$ and $\mathrm{t}=-1$, respectively. (R5) refers to the average of the indexadjusted target share prices at $t=-20, t=-5$, and $t=-1$. Finally, (R6) applies an index-adjusted base price at $t=-40$. We account for industry-specific effects with dummies for the targets' and bidders' SIC codes and include year dummies. Standard errors refer to the Huber-White (1980) estimator. ${ }^{*} \mathrm{p}<0.05,{ }^{* *} \mathrm{p}<0.01$, and $\mathrm{p}<0.001$.

\begin{tabular}{lcccccc}
\hline & $\mathbf{( R 1 )}$ & $\mathbf{( R 2 )}$ & $\mathbf{( R 3 )}$ & $\mathbf{( R 4 )}$ & $\mathbf{( R 5 )}$ & $\mathbf{( R 6 )}$ \\
\hline TQ T & $0.143^{* * *}$ & $0.137^{* * *}$ & $0.103^{* * *}$ & $0.127^{* * *}$ & $0.141^{* * *}$ & $0.068^{*}$ \\
TQ B & $-0.116^{*}$ & -0.056 & -0.048 & -0.061 & -0.074 & -0.005 \\
EQ & $0.011^{* *}$ & $0.013^{* * *}$ & $0.012^{* * *}$ & $0.008^{* *}$ & $0.010^{* *}$ & $0.011^{* * *}$ \\
NEW EQ50 & 0.236 & 0.256 & 0.296 & 0.338 & 0.485 & -0.068 \\
RSIZE & $0.815^{* * *}$ & $0.793 * * *$ & $0.648^{* * *}$ & $0.542^{* *}$ & $0.751^{* * *}$ & $0.475^{*}$ \\
MKT BIDS & -0.005 & -0.006 & 0.002 & 0.000 & -0.002 & 0.004 \\
MKT VOL & -0.055 & $-0.042^{*}$ & -0.061 & -0.036 & -0.051 & -0.046 \\
NUMBID & 0.684 & 0.219 & 0.400 & 0.527 & 0.000 & -0.383 \\
TENDER & -0.318 & -0.402 & -0.348 & -0.432 & -0.255 & -0.131 \\
HORIZONTAL & 0.075 & 0.186 & 0.089 & -0.036 & -0.064 & -0.088 \\
WITHDRAWN & 0.349 & 0.415 & 0.094 & -0.298 & 0.038 & 0.426 \\
HOSTILE & -0.650 & -0.101 & -0.693 & -0.929 & -0.624 & 0.994 \\
\hline ll & -316.084 & -403.191 & -372.755 & -449.331 & -355.574 & -401.945 \\
aic & 716.168 & 878.382 & 829.511 & 984.662 & 791.148 & 887.890 \\
bic & 946.204 & $1,075.555$ & $1,057.501$ & $1,220.126$ & $1,008.234$ & $1,117.423$ \\
r2 p & 0.153 & 0.159 & 0.112 & 0.112 & 0.130 & 0.102 \\
N & 1,767 & 1,767 & 1,683 & 1,765 & 1,681 & 1,746 \\
\hline
\end{tabular}




\section{Table W2. Robustness to Cash Mergers and Multiple Bids}

(R7) and (R8) replicate (A) and (B) excluding cash mergers, respectively. (R9) and (R10) replicate Specifications (A) and (B) after removing multiple bids. The main findings that the positive impact of a target's valuation (TQ T), equity portion (EQ), relative size (RSIZE), and the hidden earnout measure (HE) and the negative impact of market volume (MKT VOL) are not affected by the exclusion of cash mergers or multiple bids. We account for industry-specific effects with dummies for the targets' and bidders' SIC codes and include year dummies. Standard errors refer to the Huber-White (1980) estimator. ${ }^{*} \mathrm{p}<0.05,{ }^{* *} \mathrm{p}<0.01$, and ${ }^{* * *} \mathrm{p}<$ 0.001 .

\begin{tabular}{lcccc}
\hline & $\mathbf{( R 7 )}$ & $\mathbf{( R 8 )}$ & $\mathbf{( R 9 )}$ & $\mathbf{( R 1 0 )}$ \\
\hline TQ T & $0.140^{* * *}$ & $0.149^{* * *}$ & $0.152^{* * *}$ & $0.156^{* * *}$ \\
TQ B & -0.081 & -0.101 & $-0.090^{*}$ & $-0.118^{*}$ \\
EQ & $0.019^{*}$ & $0.015^{*}$ & $0.010^{* * *}$ & $0.018^{* * *}$ \\
NEW EQ50 & 0.350 & 0.881 & 0.799 & $1.545^{* *}$ \\
RSIZE & $1.005^{* * *}$ & $1.579^{* * *}$ & $0.689^{* * *}$ & $0.716^{*}$ \\
BIG T & & 0.204 & & 0.385 \\
HE & & $21.112^{* * *}$ & & $19.077^{* * *}$ \\
MKT BIDS & -0.008 & 0.001 & -0.006 & 0.002 \\
MKT VOL & -0.086 & $-0.079^{* *}$ & $-0.073^{*}$ & $-0.065^{* *}$ \\
NUMBID & 0.696 & 0.252 & & \\
TENDER & -1.251 & -0.733 & -0.323 & -0.345 \\
HORIZONTAL & 0.247 & 0.398 & 0.193 & 0.293 \\
WITHDRAWN & 0.167 & 0.217 & 0.106 & 0.194 \\
HOSTILE & 0.000 & 0.000 & 0.117 & 0.303 \\
\hline ll & -309.379 & -224.212 & -398.265 & -319.476 \\
aic & 700.758 & 534.424 & 864.530 & 726.953 \\
bic & 904.016 & 746.895 & $1,049.495$ & 965.643 \\
r2 p & 0.157 & 0.368 & 0.147 & 0.294 \\
N & 1,051 & 1,034 & 1,703 & 1,677 \\
\hline & & & & \\
\hline & & & & \\
\hline
\end{tabular}




\section{Table W3. Determinants of Negative Premiums with Additional Liquidity Measures}

Logistic regressions explain negative premiums. We extend the reference Model (A) in Table IV by including stock market liquidity measures (ZERO, SPREAD) in (E1), a dummy for distressed targets based on Altman's Z-score (Z DISS) in (E2), the Altman's Zscore (Z SCORE) in (E3), and the WW index measuring targets' financial constraints in (E4). We account for industry-specific effects with dummies for the targets' and bidders' SIC codes and include year dummies. Standard errors refer to the Huber-White (1980) estimator. ${ }^{*} \mathrm{p}<0.05,{ }^{* *} \mathrm{p}<0.01$, and ${ }^{* * *} \mathrm{p}<0.001$.

\begin{tabular}{|c|c|c|c|c|}
\hline & (E1) & (E2) & (E3) & (E4) \\
\hline TQ T & $0.138^{* * *}$ & $0.103^{*}$ & $0.088^{*}$ & $0.087^{*}$ \\
\hline TQ B & $-0.094 *$ & -0.088 & -0.078 & -0.050 \\
\hline EQ & $0.010 * *$ & $0.008^{*}$ & $0.008^{*}$ & $0.008^{*}$ \\
\hline NEW EQ50 & 0.678 & 0.107 & 0.108 & 0.179 \\
\hline RSIZE & $0.791 * *$ & $0.755^{*}$ & $0.771 * *$ & $1.000 * * *$ \\
\hline MKT BIDS & -0.003 & -0.001 & -0.001 & -0.003 \\
\hline MKT VOL & $-0.118 * *$ & $-0.130 * *$ & $-0.134 * *$ & $-0.143 * *$ \\
\hline ZERO & 0.793 & & & \\
\hline SPREAD & 0.057 & & & \\
\hline Z DISS & & -0.036 & & \\
\hline Z SCORE & & & 0.000 & \\
\hline WW & & & & $0.001 * * *$ \\
\hline NUMBID & 0.259 & 0.487 & 0.493 & 0.444 \\
\hline TENDER & -0.404 & -0.360 & -0.351 & -0.435 \\
\hline HORIZONTAL & 0.132 & 0.282 & 0.271 & 0.268 \\
\hline WITHDRAWN & 0.222 & 0.125 & 0.125 & 0.121 \\
\hline HOSTILE & -0.930 & -1.009 & -1.025 & -1.010 \\
\hline 11 & -317.006 & -209.633 & -209.046 & -226.525 \\
\hline aic & 722.012 & 491.266 & 482.093 & 531.050 \\
\hline bic & 955.233 & 664.668 & 636.229 & 722.296 \\
\hline $\mathrm{r} 2 \mathrm{p}$ & 0.152 & 0.151 & 0.154 & 0.164 \\
\hline $\mathrm{N}$ & 1,481 & 913 & 913 & 996 \\
\hline
\end{tabular}




\section{Table W4. Determinants of Low Premiums (LPs) Using Logistic Regressions}

(E5) is the reference model. (E6) and (E7) decompose valuation levels. (E8) includes the direct measure of hidden earnouts. (E9) focuses on targets' profitability and (E10) on financial health. We account for industry-specific effects with dummies for the targets' and bidders' SIC codes and include year dummies. Standard errors refer to the Huber-White (1980) estimator. ${ }^{*} \mathrm{p}<0.05,{ }^{* *} \mathrm{p}<0.01$, and ${ }^{* * *} \mathrm{p}<0.001$.

\begin{tabular}{|c|c|c|c|c|c|c|}
\hline & (E5) & (E6) & (E7) & (E8) & (E9) & (E10) \\
\hline TQ T & $0.142 * * *$ & & & $0.160 * * *$ & $0.126^{*}$ & $0.105 * *$ \\
\hline TQ B & $-0.106 * *$ & & & $-0.124 * *$ & $-0.149 *$ & $-0.071^{*}$ \\
\hline FIRM T & & $0.186^{* *}$ & & & & \\
\hline SECTOR T & & $0.223 *$ & & & & \\
\hline LONG T & & $0.561 * * *$ & & & & \\
\hline FIRM B & & & 0.037 & & & \\
\hline SECTOR B & & & 0.173 & & & \\
\hline LONG B & & & 0.281 & & & \\
\hline EQ & $0.010 * * *$ & $0.007 * * *$ & $0.007 * * *$ & $0.018^{* * *}$ & $0.016 * * *$ & $0.010 * *$ \\
\hline NEW EQ50 & 0.628 & 0.172 & 0.166 & $1.170 *$ & 0.578 & 0.287 \\
\hline RSIZE & $0.755^{* * *}$ & $0.863 * * *$ & $0.802 * * *$ & 0.375 & 0.318 & $0.777 * * *$ \\
\hline BIG T & & & & $1.130 * * *$ & $1.171^{*}$ & \\
\hline $\mathrm{HE}$ & & & & $19.227 * * *$ & $23.283 * * *$ & \\
\hline ROIC & & & & & 0.004 & \\
\hline TURNOVER & & & & & 0.170 & \\
\hline $\mathrm{CI}$ & & & & & 0.078 & \\
\hline MKT BIDS & -0.004 & -0.006 & -0.004 & 0.002 & 0.001 & -0.002 \\
\hline MKT VOL & $-0.055^{*}$ & -0.009 & -0.011 & $-0.049 *$ & -0.041 & -0.078 \\
\hline LEVERAGE & & & & & & $-0.283^{*}$ \\
\hline SHORT DEBT & & & & & & 0.381 \\
\hline CASH TA & & & & & & 1.043 \\
\hline WC TA & & & & & & $-1.287^{*}$ \\
\hline LIAB & & & & & & -0.077 \\
\hline NUMBID & 0.160 & 0.499 & 0.422 & -0.457 & -0.548 & 0.200 \\
\hline TENDER & -0.280 & -0.202 & -0.205 & -0.210 & -0.300 & -0.132 \\
\hline HORIZONTAL & 0.065 & 0.062 & 0.081 & 0.102 & 0.400 & 0.085 \\
\hline WITHDRAWN & 0.280 & 0.105 & 0.070 & 0.310 & 0.192 & 0.183 \\
\hline HOSTILE & -0.106 & 0.338 & 0.265 & 0.053 & 0.301 & -0.164 \\
\hline 11 & -482.535 & -917.433 & -902.132 & -380.648 & -230.693 & -272.352 \\
\hline aic & $1,047.070$ & $1,914.866$ & $1,882.265$ & 851.296 & 523.385 & 628.704 \\
\hline bic & $1,271.629$ & $2,134.106$ & $2,095.179$ & $1,097.069$ & 678.480 & 836.437 \\
\hline $\mathrm{r} 2 \mathrm{p}$ & 0.138 & 0.081 & 0.073 & 0.297 & 0.287 & 0.143 \\
\hline $\mathrm{N}$ & 1,767 & 1,774 & 1,736 & 1,740 & 1,100 & 1,039 \\
\hline
\end{tabular}




\section{Table W5. Alternative Windows for CARs}

The second step of the sequential logistic models distinguishing between negative premiums that remain negative, with a PAP base price at $t=5$, and those that become positive ( 1 if PAP $<0 ; 0$ if PAP $\geq 0$ ), which is in line with Table VI. To compare different windows for cumulated abnormal returns, the standard model (Q) is reported, which uses a window from $t=-1$ to $t=1$. Alternative windows for the bidder's and target's cumulated abnormal returns based on $[-1,5]$ in $\mathrm{E}(11),[-1,20]$ in $\mathrm{E}(12)$ and $[-1,60]$ in $\mathrm{E}(13)$ are reported. We account for industry-specific effects with dummies for targets' and bidders' SIC codes and include year dummies. Standard errors refer to the Huber-White (1980) estimator. ${ }^{*} \mathrm{p}<0.05,{ }^{* *} \mathrm{p}<0.01$, and ${ }^{* * *} \mathrm{p}<0.001$.

\begin{tabular}{|c|c|c|c|c|}
\hline & (Q) & (E11) & (E12) & (E13) \\
\hline TQ T & -0.010 & 0.079 & 0.025 & 0.021 \\
\hline TQ B & $0.256^{*}$ & 0.159 & 0.184 & $0.283^{*}$ \\
\hline $\mathrm{HE}$ & $19.504 *$ & 12.683 & 14.169 & 13.013 \\
\hline CAR B & $9.100 *$ & & & \\
\hline CAR T & $5.766^{* *}$ & & & \\
\hline CAR B 5d & & 4.532 & & \\
\hline CAR T 5d & & $6.592 *$ & & \\
\hline CAR B 20d & & & -0.193 & \\
\hline CAR T 20d & & & $3.232 *$ & \\
\hline CAR B 60d & & & & -2.827 \\
\hline CAR T 60d & & & & $3.399 *$ \\
\hline EQ & -0.008 & -0.012 & -0.014 & -0.013 \\
\hline RSIZE & -0.229 & -0.366 & -0.550 & 0.242 \\
\hline BIG T & $-10.877 * * *$ & $-8.994 * *$ & $-8.853 * *$ & $-11.599 * *$ \\
\hline EQxBIG T & $0.132 * * *$ & $0.115^{* * *}$ & $0.119^{* * *}$ & $0.144 * * *$ \\
\hline MKT BIDS & 0.010 & 0.014 & 0.006 & 0.000 \\
\hline MKT VOL & -0.337 & $-0.361^{*}$ & $-0.457^{*}$ & $-0.451^{*}$ \\
\hline NUMBID & 1.611 & 1.001 & 0.057 & -0.683 \\
\hline TENDER & -0.626 & -1.047 & -0.714 & -3.739 \\
\hline HORIZONTAL & $1.754^{*}$ & 1.259 & 1.285 & 1.181 \\
\hline WITHDRAWN & -1.098 & -1.130 & -1.167 & -1.117 \\
\hline HOSTILE & $7.422^{* *}$ & $6.174 *$ & $6.765^{* *}$ & $10.542 * * *$ \\
\hline 11 & -45.344 & -45.207 & -48.152 & -41.343 \\
\hline aic & 174.689 & 174.413 & 180.304 & 164.686 \\
\hline bic & 294.801 & 294.526 & 299.760 & 276.144 \\
\hline $\mathrm{r} 2 \mathrm{p}$ & 0.488 & 0.489 & 0.446 & 0.461 \\
\hline $\mathrm{N}$ & 129 & 129 & 127 & 112 \\
\hline
\end{tabular}




\section{Table W6. Alternative Proxies for Overvaluation}

To compare different measures of overvaluation, the reference Model (A) in Table IV is reported, which uses Tobin's Q. (E14) reports operating accruals (ACCR), while net operating assets (NOA) are shown in Model (E15). Specification (E16) uses the price-to-residual income-model-value (PRIMV) with a constant discount rate of $12.5 \%$ and a three-year window. We account for industry-specific effects with dummies for the targets' and bidders' SIC codes and include year dummies. Standard errors refer to the Huber-White (1980) estimator. ${ }^{*} p<0.05,{ }^{* *} p<0.01$, and ${ }^{* * *} p<0.001$.

\begin{tabular}{lcccc}
\hline & $(\mathbf{A})$ & $\mathbf{( E 1 4 )}$ & $\mathbf{( E 1 5 )}$ & $\mathbf{( E 1 6 )}$ \\
\hline TQ T & $0.144^{* * *}$ & & & \\
TQ B & $-0.094^{*}$ & & & \\
ACCR T & & 0.645 & & \\
ACCR B & & 0.183 & & \\
NOA T & & & 0.195 & \\
NOA B & & -0.546 & \\
PRIMV T & & & & $0.016^{*}$ \\
PRIMV B & & & & 0.000 \\
EQ & $0.010^{* * *}$ & $0.015^{* *}$ & $0.013^{* *}$ & $0.015^{*}$ \\
NEW EQ50 & 0.597 & 1.023 & 1.044 & 0.768 \\
RSIZE & $0.772^{* * *}$ & $1.148^{* * *}$ & $1.035^{* * *}$ & $1.172^{* *}$ \\
MKT BIDS & -0.004 & -0.010 & -0.009 & -0.010 \\
MKT VOL & $-0.070^{*}$ & $-0.067 *$ & $-0.070^{*}$ & $-0.060^{*}$ \\
NUMBID & 0.511 & -0.351 & 0.271 & -0.505 \\
TENDER & -0.426 & -0.348 & -0.329 & -0.983 \\
HORIZONTAL & 0.135 & -0.114 & -0.152 & -0.144 \\
WITHDRAWN & 0.230 & 0.066 & -0.106 & 0.330 \\
HOSTILE & -0.310 & & & \\
\hline ll & -416.472 & -153.493 & -173.525 & -135.233 \\
aic & 896.944 & 382.987 & 405.051 & 346.467 \\
bic & $1,072.209$ & 551.132 & 536.782 & 512.717 \\
r2 p & 0.149 & 0.245 & 0.220 & 0.277 \\
N & 1,767 & 617 & 694 & 587 \\
\hline & & & & \\
\hline
\end{tabular}




\section{Table W7. Agency Costs and Negative Premiums}

To compare different specifications, the reference Model (A) in Table IV is reported. Models (E17) and (E18) include agency proxies, which refer to discretionary accruals (DA) and non-discretionary accruals (NDA). The residuals of Regression (7) are discretionary accruals, while the fitted values refer to non-discretionary accruals. (E18) also includes the bid-ask spread (SPREAD) as a proxy for information asymmetry. (E19)] refers to very low premiums (bottom 25\%), while (E20) explains very high premiums (top 25\%). We account for industry-specific effects with dummies for the targets' and bidders' SIC codes and include year dummies. Standard errors refer to the Huber-White (1980) estimator. ${ }^{*} \mathrm{p}<0.05,{ }^{* *} \mathrm{p}<0.01$, and ${ }^{* * *} \mathrm{p}<0.001$.

\begin{tabular}{lccccc}
\hline & $(\mathbf{A})$ & $\mathbf{( E 1 7 )}$ & $\mathbf{( E 1 8 )}$ & $\mathbf{( E 1 9 )}$ & $\mathbf{( E 2 0 )}$ \\
\hline TQ T & $0.144^{* * *}$ & $0.153^{* *}$ & $0.136^{*}$ & $0.124^{* *}$ & -0.094 \\
TQ B & $-0.094^{*}$ & -0.069 & -0.028 & -0.042 & 0.036 \\
DA T & & 1.198 & $1.689^{*}$ & 0.117 & $-0.775^{*}$ \\
DA B & & 0.708 & -0.504 & -0.375 & 1.293 \\
NDA T & & -1.577 & -2.406 & -2.296 & 1.878 \\
NDA B & & -1.015 & -2.683 & 0.320 & -0.775 \\
SPREAD & & & 0.049 & -0.034 & -0.009 \\
EQ & $0.010^{* * *}$ & $0.014^{* *}$ & 0.011 & $0.009^{* *}$ & 0.002 \\
NEW EQ50 & 0.597 & 0.821 & 1.316 & -0.618 & 0.918 \\
RSIZE & $0.772^{* * *}$ & $1.170^{* * *}$ & $1.399^{*}$ & $1.279^{* * *}$ & $-1.964^{* *}$ \\
MKT BIDS & -0.004 & -0.012 & -0.011 & -0.009 & 0.003 \\
MKT VOL & $-0.070^{*}$ & $-0.074^{*}$ & $-0.127^{* *}$ & -0.010 & 0.002 \\
NUMBID & 0.511 & -0.632 & -0.001 & -0.258 & -1.107 \\
TENDER & -0.426 & -0.306 & -0.205 & -0.119 & 0.333 \\
HORIZONTAL & 0.135 & -0.183 & -0.013 & -0.196 & 0.365 \\
WITHDRAWN & 0.230 & 0.062 & 0.033 & 0.540 & -0.563 \\
HOSTILE & -0.310 & & & 0.861 & 0.208 \\
\hline ll & -416.472 & -143.476 & -116.596 & -259.983 & -275.690 \\
aic & 898.944 & 370.952 & 315.191 & 613.967 & 627.380 \\
bic & $1,079.686$ & 554.917 & 487.246 & 818.622 & 792.514 \\
r2 p & 0.149 & 0.269 & 0.258 & 0.147 & 0.155 \\
$\mathrm{~N}$ & 1,767 & 590 & 491 & 575 & 570 \\
\hline
\end{tabular}

